فعالية معالمات التركيب الهنسي النسبي في فاومة فاذ لألول الموجية الضارة للأشعةفوق البفسجية خلال الملابس الخارجية

جيهان محمود عبدالحميد، وفاء محمد محمسملحة I

فوق البفسجية القوية التي تصدرها اللثمس ويتكون

الأوزون من ثلاث ذرات أوكسجين (IN)

ولهذ الطقة أهمية حيوية للإنسان فهي تحول دون وصول الموجلت فوق البفسجية القصيرة بتركيز كبير إلى اله سطح الأرض حيث ققوم طقة الأوزون بترشبيح أوفلترة

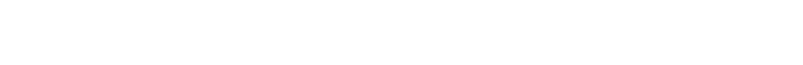
الإنسان والكائنت الحية الأخرى علسطحح الأرض (r) ومنذ عدة عقود يعانيسكان الأرض من لمتنزف هنه الطقة الواقية الطبيعية للأوزون عن طريق الإنيان الكيماويت

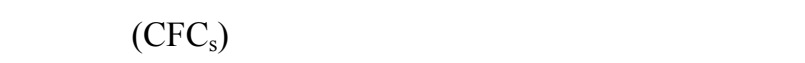
من المواد التي تستخدم في صناعة الحاويت الغذائية

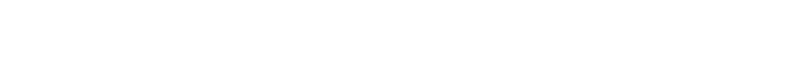

الحراري للمنازل (17)

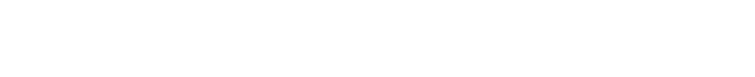

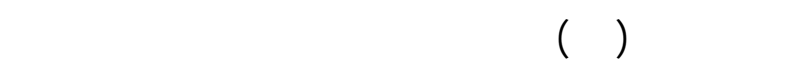

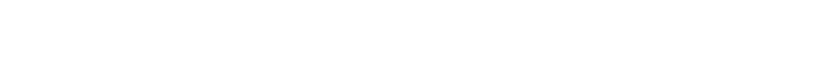

الجوي (19)

والأشعة فوق البفسجية أيَا كلن مصدرها طبيعي

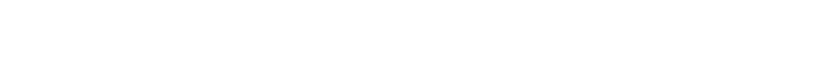

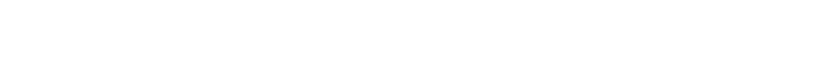

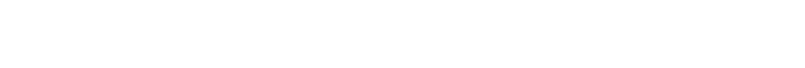

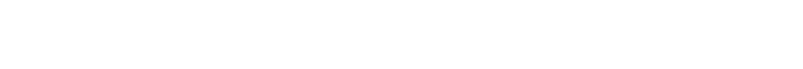

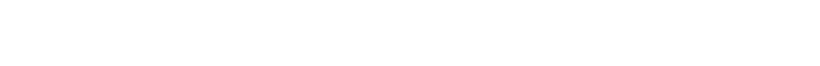

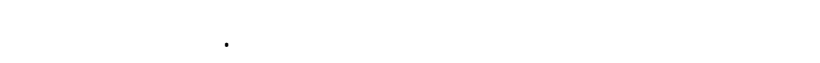
خطورة هذه الأشعة على الإنسان والكائنت الحة الحية الأخرى

\section{الملغص العرى}

تمل الملابس الخارجية فيزقيا النلف الخارجي المسئل

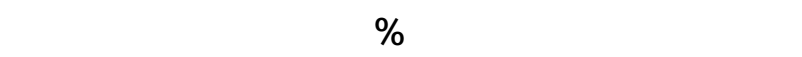

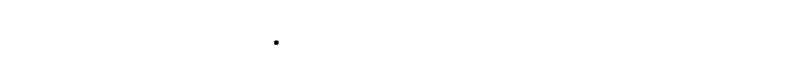

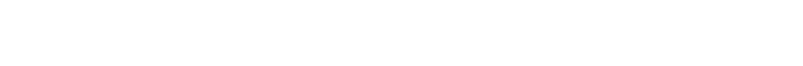

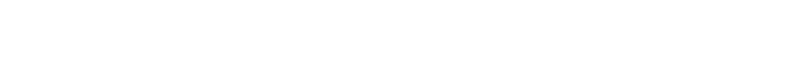

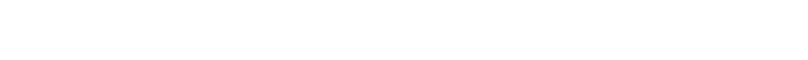

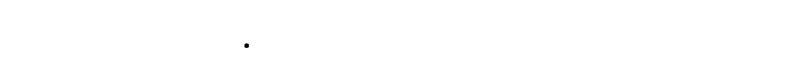
العينلت المصنعة من البولي المتر الخالص ومن البواء البول لمستر

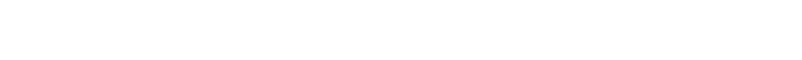

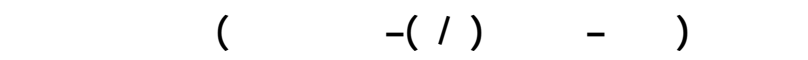

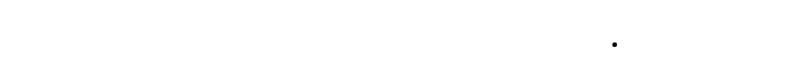

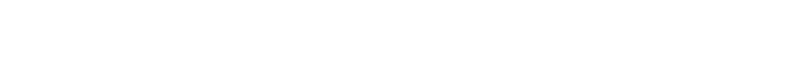
عل منحنيلت طلفية تبين معل فاذ الأشهة فوق البفسجية

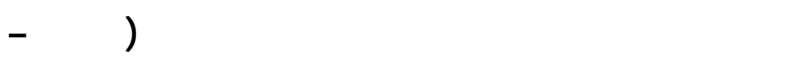

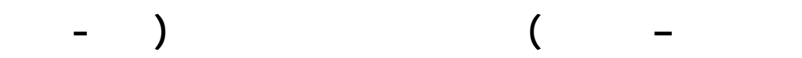
نالنوميتر) ولسنخمت الوسلال الإحصائية الحيثة لإيجاد

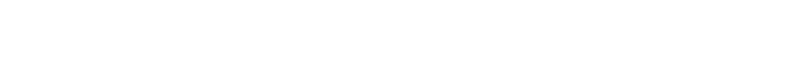
لكالل بيبوسون(PPCC) من ألمل تحصيد المعليير المثل لاختيار

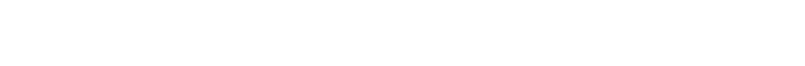
النسبي.

\section{المقه ـ ـة والمشكلة البحثية}

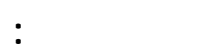

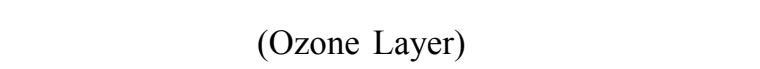

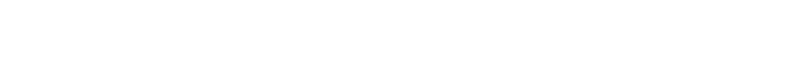

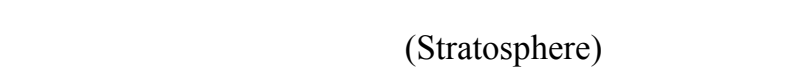

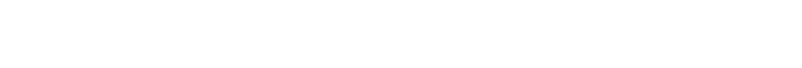

1 قسم النبج والملابس - كلية التربية النوعية -جلمعة المنصورة

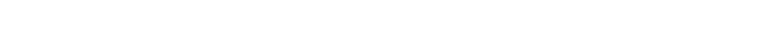


وترجع اهمية البهث اله الكثف عن فعالية الهنهة

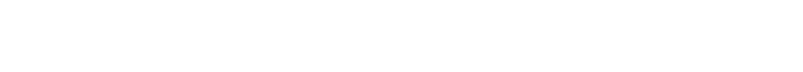

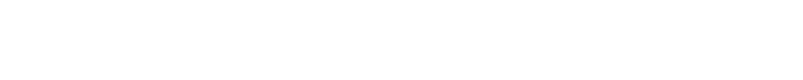

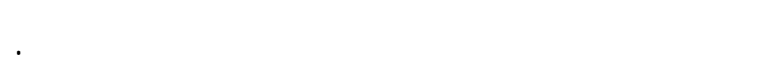

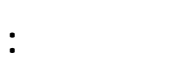
1 - أهمية علمية: تحديد العلاقلت الرياضية والفيزيقية بين المعلملات البنائية الهنهية وخواص الفاذ ممثلة في الفيد الخواص الضوئية للأشعة.

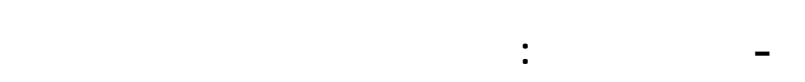
الضارة بالإنسان عن طريق التحكم الهiهي النسجي

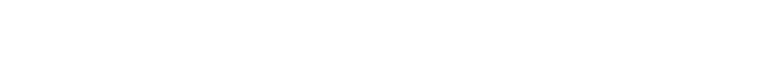

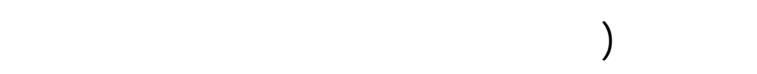
البفسجية).

r - ألهية صصية: من المعروف أن أي معالجلت كيميائية تجهيزية تجررى على الأقمشة نقل من خواصها الصحية

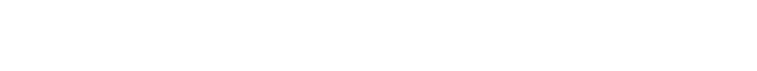

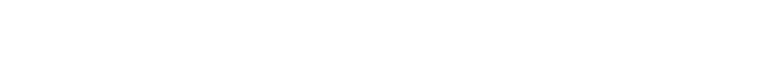
يساهم في مقاومة الاثعة الضارة اللى الجم.

أنسلف البهث:

يموف البهث إلى تحديد العلاقت الفيزيقية والإحصائية

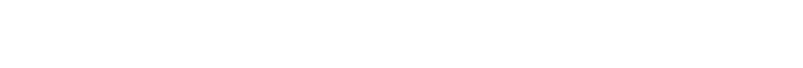

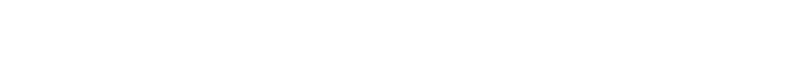

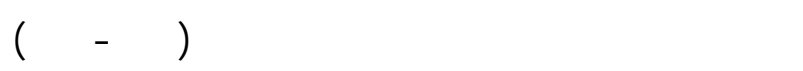
نانوميتر للكثف عن أمل التركيبت الهنهية النسجية بمعلملاتها الهنهية للمستخده كأقمشة صحية واقية من

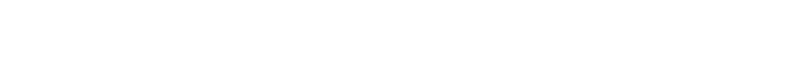
البفسجية.

\section{التساؤلات البحثية:}

- هل تلعب الطبيعة البنائية النسجية في الأفمشة المختلفة

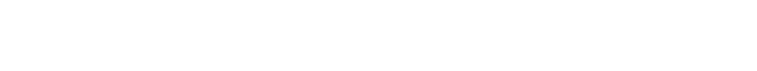

أنها أشعة مؤينة "Ionizing Radiation" لخلايا الأجسلم التي يتعرض لها. بمعنى أنها تقصل الإلكترونات عن ذرالتها مما

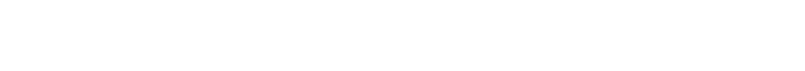
المواد متوهجة أو ملتهبة (0)، ومن المعروف أن التأنين يقود إله تغييرات جزيئية في الماء الذي تتكون منه خلايا الجنم، وينبق من هذه التغييرات الجزيئية فصال كيماوية

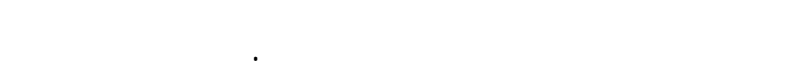

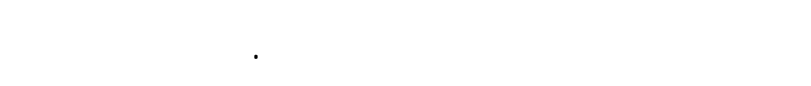
هذه التغيرات في الجمم البثري كآثار مرضية مل غئل غثيلن أوعدم الرؤية بوضوح أو السرطلن على المدى البعيد( ب).

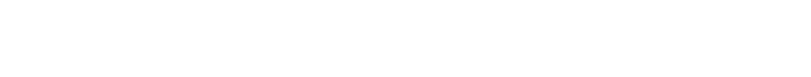

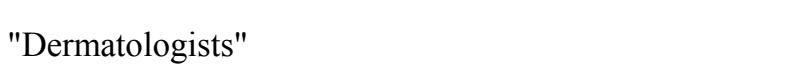

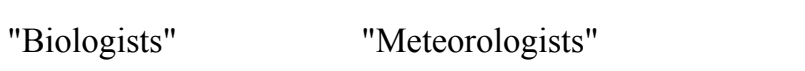

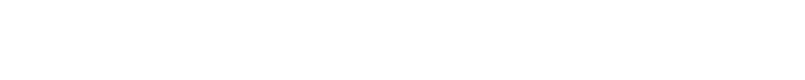
والطالبة بضرورة توفير حماية منظمة وفعالة بلستخدلم وسالل الحماية الذاتية للمساهمة في الوقاية الفعالة منها. والملابس بهنهسة تركيباتها للشعرية المتعدة يمكن أن

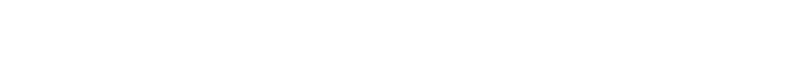

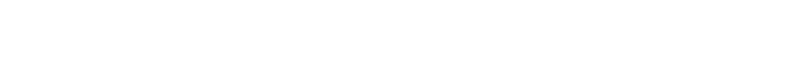

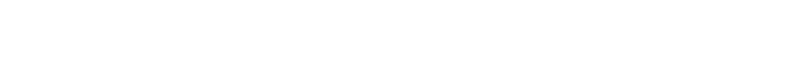
على جهم الإنسلن.

مشكالة البهث:

ظرأ لأن الملابس الخارجية تمل فيزيقيا الغلاف

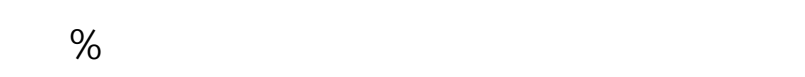

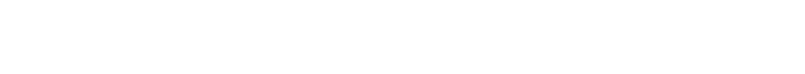
الإنسل. لذاك تنحصر المشكلة العلمية لهذا البحث في الكثف عن فعالية هنهسية البناء النسجي لمنسوجلت الملابس الذابن الخارجية بكل معلملاتها في التحكم في مقاومة فاذ الأطول

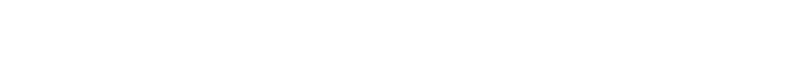
الجمم. 


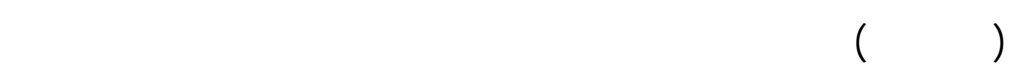

التع البهث المنهج التجريبي والمنهج التحليلي.

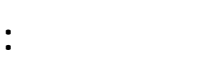

الحود المكلنية: لقد مّ لجراء البهث فى بالمركز القومي

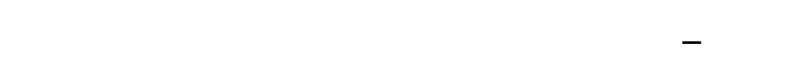

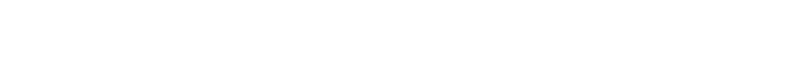

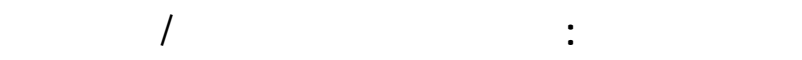

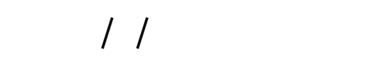

المصمالحكت اللالمية:

الموجلت الكهروغغلليسية فوق البفسجية (UV):

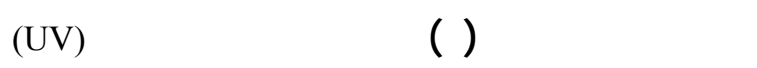

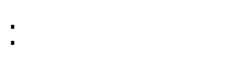

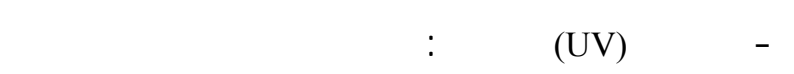

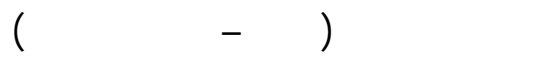

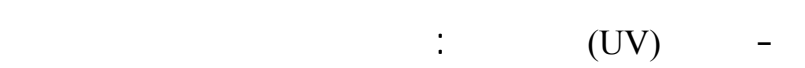

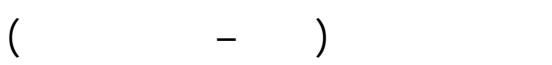

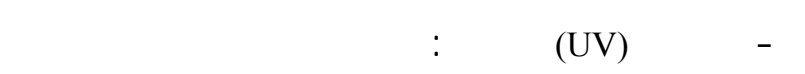
موجاتها ما بين (· (1 - . - انانوميتر)

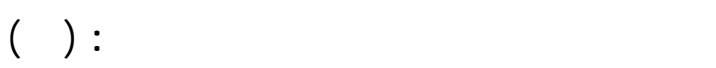

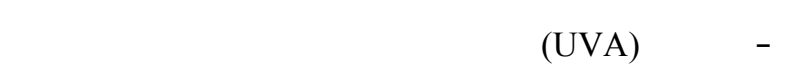

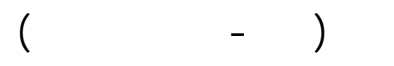

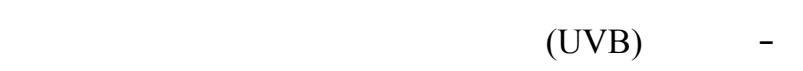

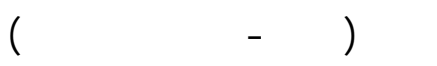

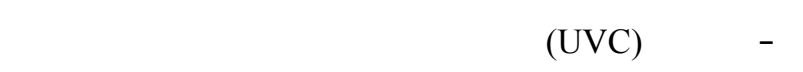

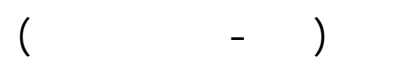

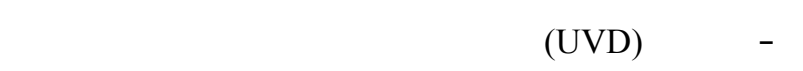
بين (· - . - ا بنانوميتر)
الآخر بلختلاف معلملات تركيبها النسجي.

- هل يترتب على التحكم الهنهي في معلملات البناء

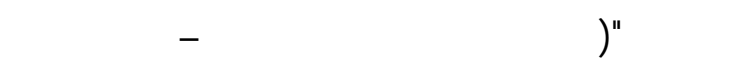

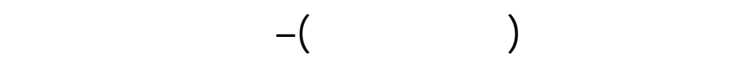
'القملشاسداء ولحمة)' إحداث تغير جذري في كل من: الفتحكت البينية النسجية- نقلص الخيوط الذي يؤيون بدوره إلى تغييرسمك القملا الملبيه.

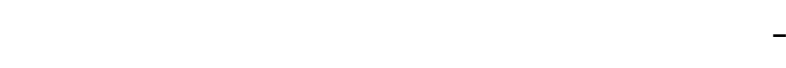
القملث تأثيراً جذرياً على فاذ الأطول الموجية الضارة للمأشعة فوق البفسجية.

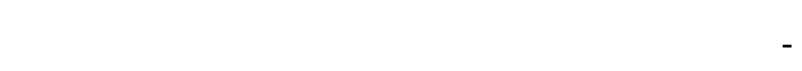
الاشعة فوق البفسجية (uv) وتفوق في ذلك الأليف التركيبية.

\section{الأسلوب البحث}

اللرف الميتولوجية (المتطفة بالمناخ): لجواء حارة جلفة

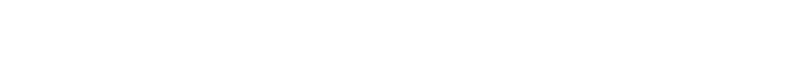

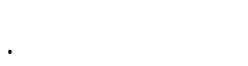

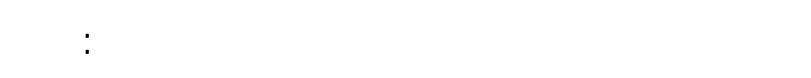

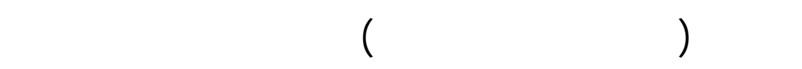
(للسداء واللحمة)، والكثافة العددية للخيوط/سنتيمتر (للسداء النياء

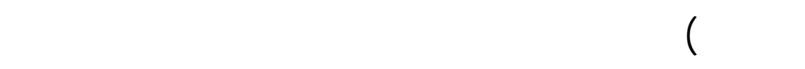
القملاث(مسلمية الفتحلت البينية)، وسمك القملثال بالمليمتر، ووزن المتر المريع (جه dr") عينت البهث مصفة من أقمشة خففة الوزن من: خلملت تركيبية خالصة(بولي لإستر)- خلمات تركيبية الميبية مخلوطة (بولي لستر + بولى أميد).

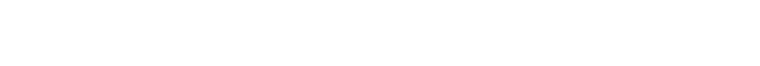
الدرلسة (. - - -.-ع) نانوميتر. 
ثلاث المحاور يوجد ظلمين للسداء وظلم ولحد للحملت.

الدرلسة القالربة

وتمل معلملات التركيب الهنهسي النسجي عناصر التحكم الأسلسية في جمبع خواص المنتج النسجي الجمالية والفيزيقية، وبشكل علم يمكن تحديد هذه المعلملات فيما يلي:

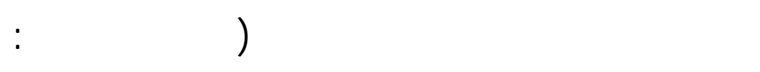
الخواص الفيزيقية والبعية، والخواص الميكانيكية، وخواص الخاص الامتصاص، والخواص الحرارية، والخواص الكيميائية،

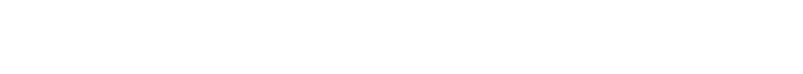

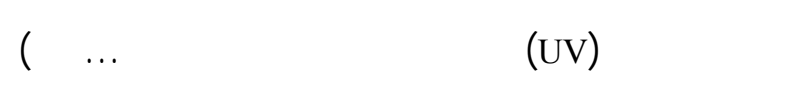
وتشهل المعلملات الهنهسية للخيوط (نوع الخيوط،

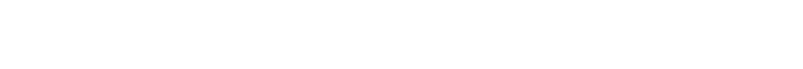
للخط، وعدد الشعيرات في مقطع الخط، و درجة أولس ألس الخطول

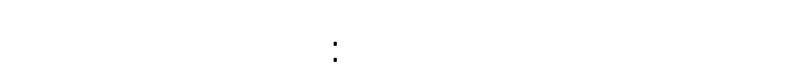
(أي المسلفت البينية بين الخيوط) ... الخ). . (ب، 0) كما تشمل معلملات هنهسة القملث المنسوج، ومعلملات زخرفة القملث المنسوج (زخارف للسداء، وخارف اللحمة،

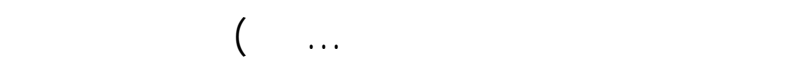

$$
\text { معلملات المعالجك التجهيزية. }
$$

ويمكن تصنيف معلملات التركيب الهنهي النسجي إله معلملات أسلسية ولخرى ثالفوية: (11 ال، ع I) المعلملات الهنهية الأسلسية: تشمل سمك الخيوط، ولخدية

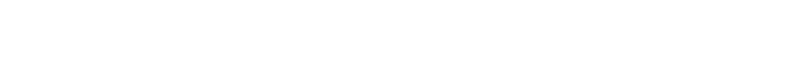
سمك الخيوط والتركيب النسجي علملان مسنقلان لما الكثلفة

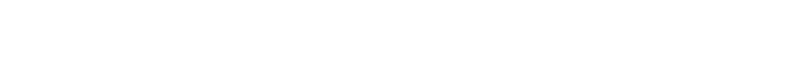
العولمل الهنهسية الأخرى تعتبر تابعة وثانوية ويبين اللثكل رقم (1) تنطيًا لهذه المعلملات:

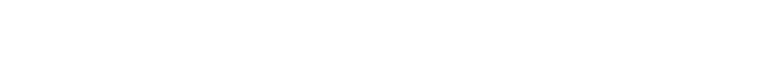
الأربعة فئت المذكورة من اللشعة فوق البفسجية (UV)

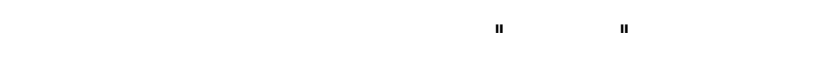

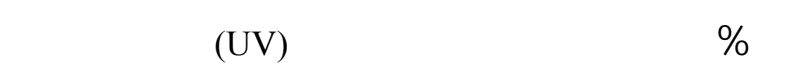

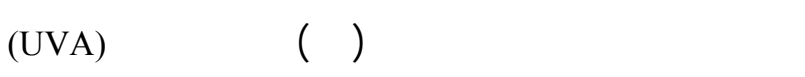
تساهم في تعجليل الشيخوخة في الجلد وتجعده حيث تلمر أليف الكولاجين تحته وقضضي على فيتلمين (A) الموجود بالجلد.

تفذ أشعة (UVA) بعمق تمت الجلد ولكنها لا تسبب حروقشمسية (Sunburns) ولكن فتط ققعشمسية. والبقع للثمسية الجلدية هي آلية دفاعية للجلد، حيث نقوم قبع الميلانين الملونة البنية بلمتصاص الثشعة (UVA) وتسريب الطاقة على هيئة حرارة غير ضارة، وتعيق بذلك الكينك

سلوك UV الذي يدمر لنسجة الجلد (0) واليوم من المعروف أن لثشعة (UVA) يمكن أن تولد وسائط كيماوية عالية الفعالية التي منشأنها أن تتلف خلايا الدي إن أية (DNA) وبهذا للثكل يحدث سروطلن الجلد، بينما تعرف أشعة (UVB) بأنها المطقة للثمسية الحارقة وتصف بانهاسبب رئيسي لسرطانت (Sunburn region) الجلد وحروق للثهس (Y). فهي نتلف العناصر البنائية الأسلسية في الحل الجيني (DNA) مبلثرة على المستوى (ل) فئل الجزئي وكذك أليف الكولاجين وفيتلمين (A) بالجلد.

\section{هنهسة البناء النسجي:}

تتكون الأفمة المنسوجة من ظم متعدة للقفطعلت الخيطية "Interlaced thread system" منظمة محورياً في التجاهات مختلفة، فمنها ثنائي المحاور "Bi-axial" وثلاثي

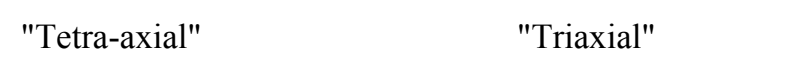
والقملث المنسوج ثنائي المحاور ظالمين متعلمدن من الخيوط:طولي (للسداء) وعرضي (اللحمل)، بينما للقملث 
معاملات خلصة لمسلسية: - خسمك الخيوط، نوع

التركيب النسج،، الكثلفة العددية للخيوطا

شلنوبة: - (تقلص الخيوط، معلمل تغطية القملث،

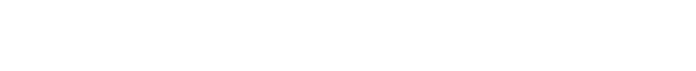
الكثلفة النوعية للقماث)

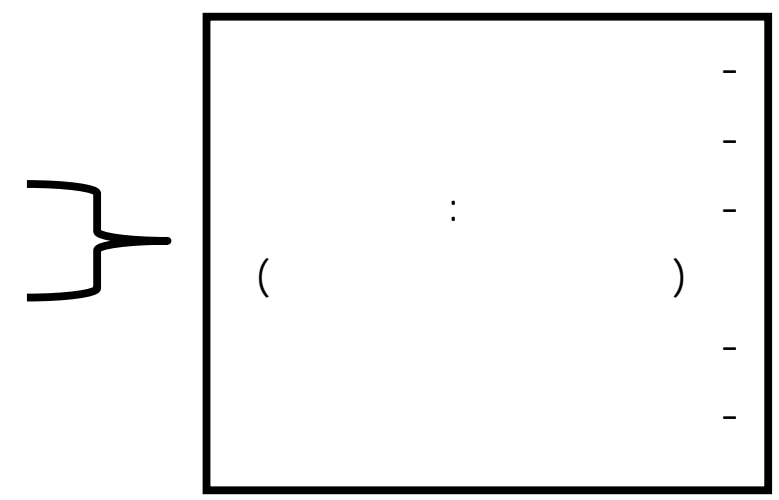

\section{شتل I. تصنيف معاللات التركيب الهنعي النسجي}

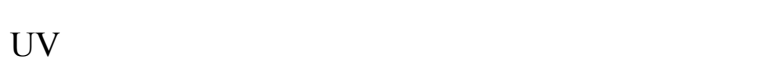
بالقيلس للأليف التركيبية رغم أن الأوله لكثر ملائمة للملابس في الأجواء الحارة. (10) وقد توصل (2005Hustvedt,et.al) أن الأقمشة الفطنية المصبوغة بالبجمينت لها خواص حماية ضد الثنهس

بالقيلس لمثيلتها التطنية المبيضة أو غير المبيضة. (V) كما لجرى (2009Stankovic et. al,) درلسة على تأثير درجة البرم على مقاومة اللشعة فوق البفسجية (UV)

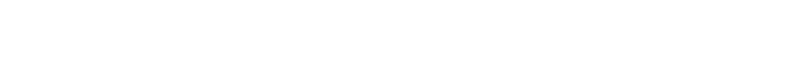

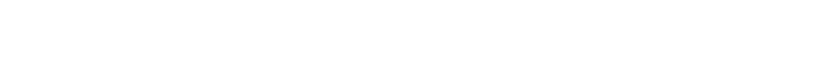

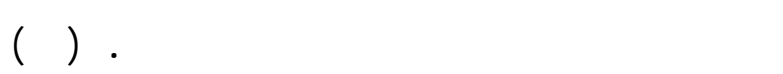
م - أثير هنسة البناء النسبي عل الوقالية من الثٔهة

\section{فوق البفسجية:}

يمر ضوء الاشعة فوق البفسجية (UV)

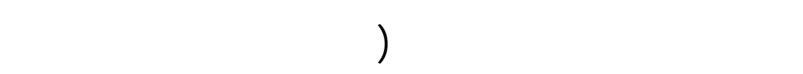
البفسجية UV) وأيضاً خلل الخيوط، حيث يغير التجاهه قل تركه للقملث (النقل تشتيتي للمشعة فوق البفسجية وقد ركزت درلست عدية على معلملات بنائية مختلفة للأفمشة لها تأثير مباثرر وهلم على الوقاية من ومن هذه المعلملات: (V، ع ا ) 1 - 1
| - تألثير التركيب الهنهم اللخيطا علم الوقلي مة ن الأشعةفوق البفسجية:

تصمم الأقمشة المنسوجة من أنواع مختلفة من الخيوط وبذلك فإن التركيب الشعري للخيط هو العلمل الفعل

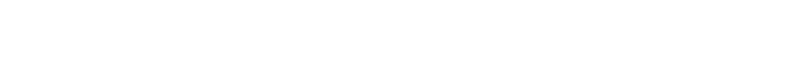

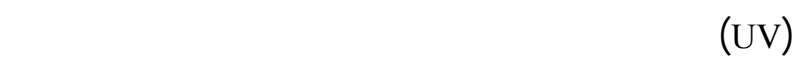
الأثعة فوق البفسجية(UV) وتمنع أغلب طلةة الإشعاع

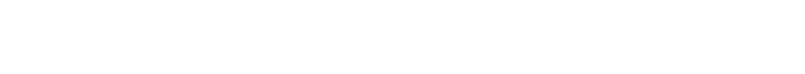

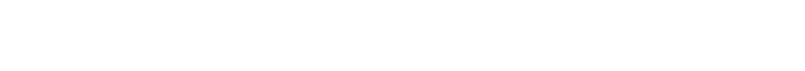

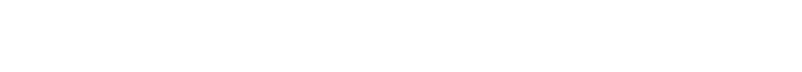

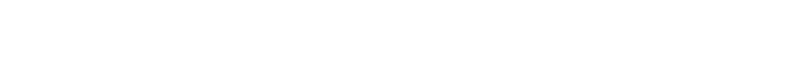

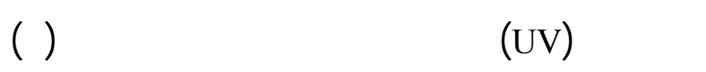
حيث لشار كلا aن (2006 Hatch \& Osterwalder,) في درلسة مقارنة بين أقمشة منسوجة غير مصبوغة وتوصلوا إله تحديد ترتيب درجة لمتصاص الأثعة فوق البفسجية للتركيبت الشعرية المختلفة في ثلاث مجموعلت (UV) (UV) نتناقص فيها قدرة لمتصاص اللثعة فوق البفسجية وهي: ا ـ مجموعة تحتوي على البولي إستر. r. مجموعة تحتوي على الصوف والحرير والبولي الميد. r. . ومجموعة تحتوي على التطن والرايون. 
كما يمكن تحوبل معلمل التغية (K)سواء كلن لأحد

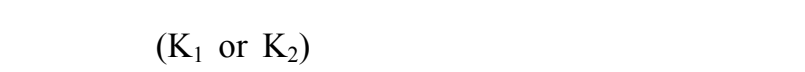

ككل (Ko إلى نسبة مئوية بلستخدلم القانون التالي ( - ():

$$
\mathrm{K} \%=\frac{\mathrm{K} \times 100}{28}
$$

أما مسلمية الفتحك النسجية فيمكن قديرها بالمعادلة (r.

$$
\frac{1}{\mathrm{Kc}}=\frac{1}{\text { الفتبح النسبي }}
$$

حيث Kc تمل النسج كلك، حيث يوضضح شكل (r)

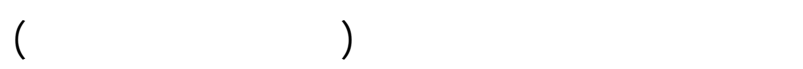

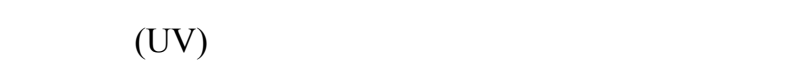
التطية (·^\%) على الأٔل (·r\% مسلمية) لتحقق وقاية

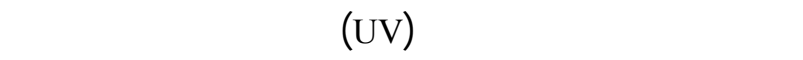

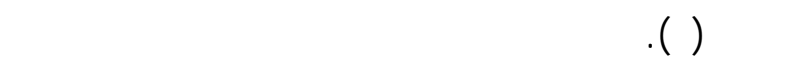
عالية وبذك لا تصلح الترلكيب النسجية المفتوحة.

$$
\text { الختيار عينالت البهث الملية البهث }
$$

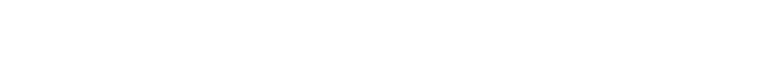
بلختلاف الخلمات المنسوجة منها: I - عينات تركيبية خالصة مصنعة من أليف البولي لمد ترك

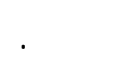
r - ع عينت تركيبية مخلوطة من كل من أليف البولي لمستر والنايلون بنسب مختلفة.

\section{الموالهفلت النسجية لهينلت الجث:}

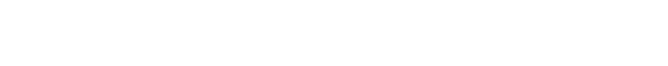
لتحليل المواصفات النسجية لعينت البهث كما يلي:

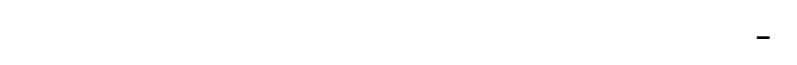

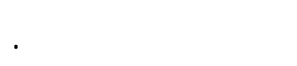

r-درجة مسلمية القملث.

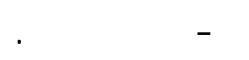
ع ع عمك القمطاش ... الخ.

r - تأثير معالل الثطية أو درجة طسامية الفتحلت النسجية:

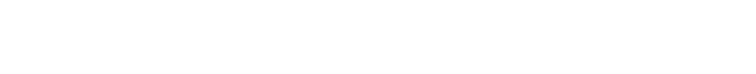

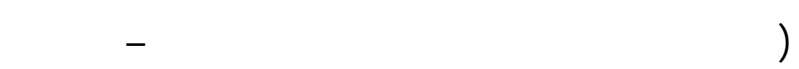
الفتحل) مع لمتبعاد العوالل الهلمة الأخرى مل الله اللون

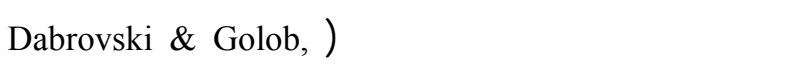

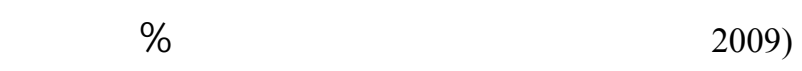

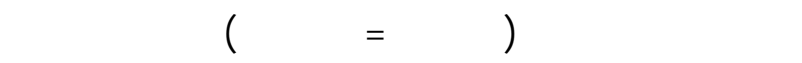

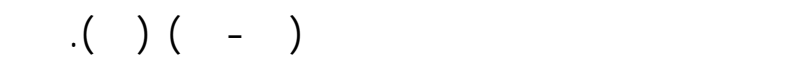

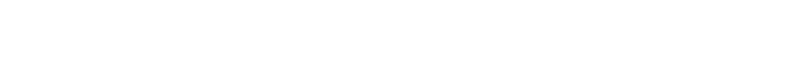
الترليب النسية (سادة -مبرد - لطألس). وقد مت ققدير(مسل) معلملات التطية ودرجة مسلمية

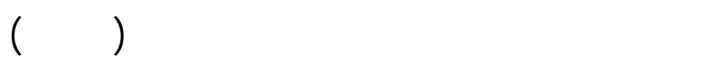

$$
\begin{aligned}
& \mathrm{K}_{1}=\frac{\mathrm{n}_{1}}{\sqrt{N 1}} \\
& \mathrm{~K}_{1}=\frac{\mathrm{N}_{2}}{\sqrt{N 2}}
\end{aligned}
$$

$\mathrm{K}_{\mathrm{c}}=$ $\mathrm{K}_{1}+\mathrm{K}_{2}+$, - معلمل تغطية خيوط للسداء. - Kع2 - Kع معل تقطية المنسوج. - n n $_{1}$ n - عدد خيوط اللحمة في البوصة.

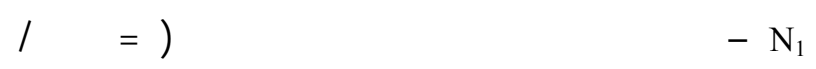
الكثلفة الطولية بالتكس) N2 - ممرة خيوط اللحمة بالظلم الإنجليزي. 


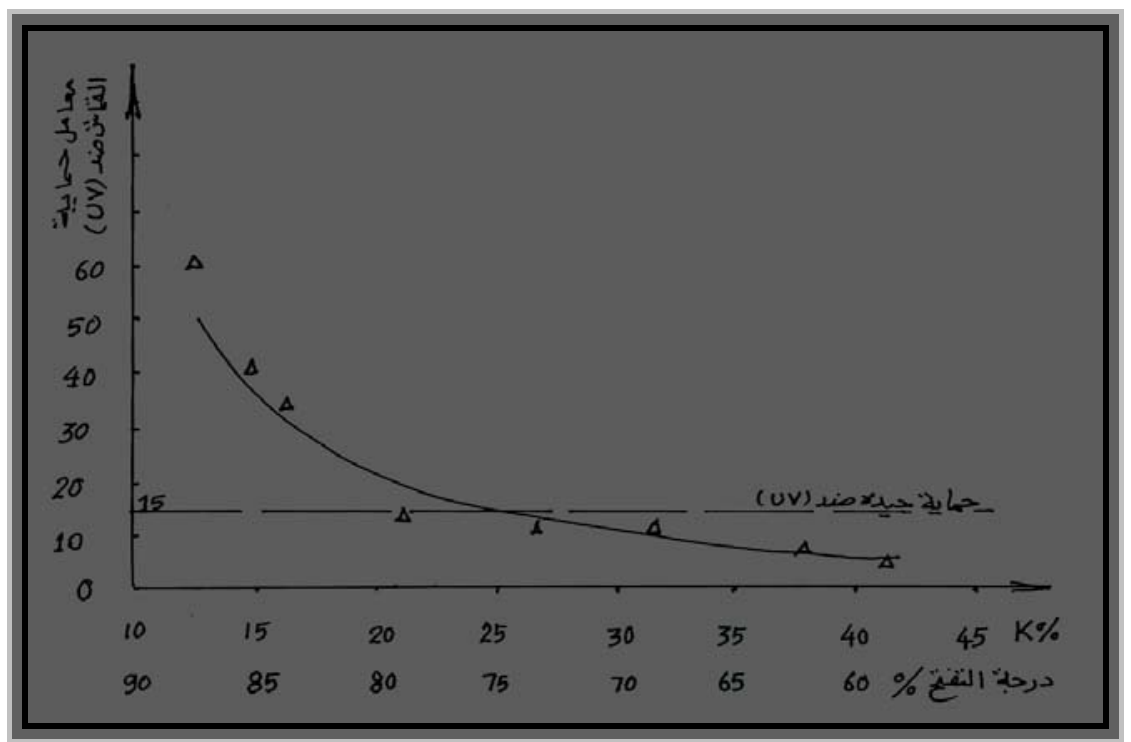

شئل r. تأثير الفيم الظاربة لمعالل النطية (K\%) أودرجة الفتح النسب (المسامية \%) علمعالل حملية الفماث الخلم (UV)دia

$$
\mathrm{K}=\frac{\mathrm{n}}{\sqrt{N}} \quad \text { كماسق اللثارة إليهما من قلب. }
$$

تحديد معلملات الفتبح النسب للأفمشة (م سلمية الفتح ـات البينية) بالقانون:

$$
\text { النسبي للنسيج = معلمل الفتبح }=\frac{1}{\text { KC }}
$$

- ققديرسمك عينات الأقمشة تحت البحث بالمليمتر.

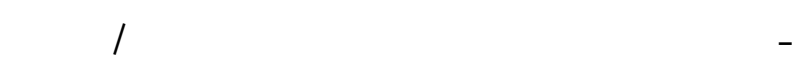

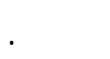

قحير فلذ الملف الكهروغنلاليمي للأشعة فوق البفسجية

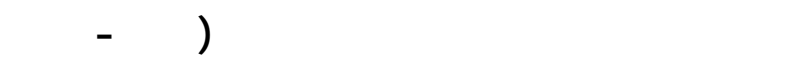

:

لستخم جهاز قيلس نفاذ الأشعة فوق البفسجية وبم لطيف الفاذ للأثشعة على المتدادطول موجلت أثشعة (UV)

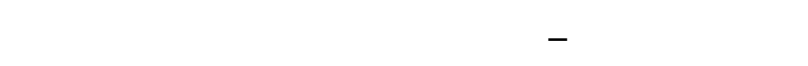
الأسبكتوفوتويتر المساح (UV-310IPC) الفيلس نفاذ الأشعة r - تحديد لنوع النسج (ومعلمل الق لطع الن سبجي) لك لـ

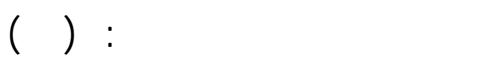
عدد تقطعلت التكرار

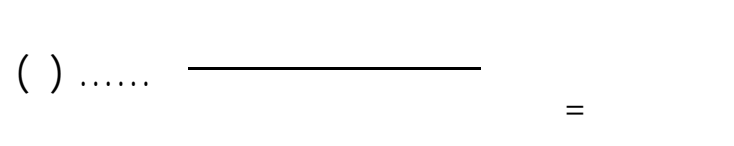

النسجي للنسج

- تحديد الكثلفة الطولية لخيوط للسداء واللحمة الم ستخدمة بالتكس والدنير. - تحديد الكثلفة العددية النسجية (عدد خيوط للسداء واللحمة / وحدة المسلحة (مقدرة بللسنتيمتر) - تحديد معلملات التطية لعينات الأقمشة تح ـت البح ثـ اث

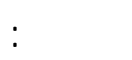
معلمل تغطية القملث (KC)= معلمل تغطية خيوط ال سداء (K2) $\left(K_{1}\right)$

$$
\mathrm{K}_{\mathrm{c}}=\quad \mathrm{K}_{1}+\mathrm{K}_{2}
$$

ومسلب معلمل تغطية خيوط للسداء (K) خيوط اللحمة (K2) بلستخدلم القانون: 


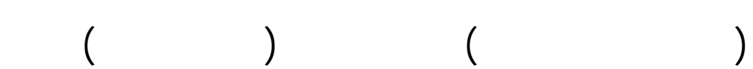

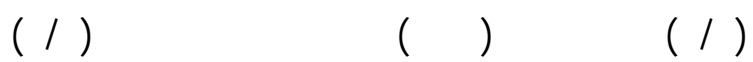
اللعينة رقم (ع).

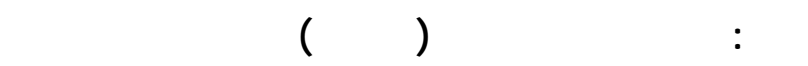

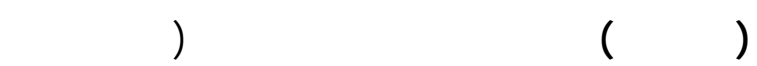

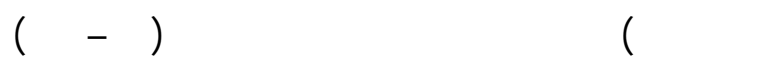

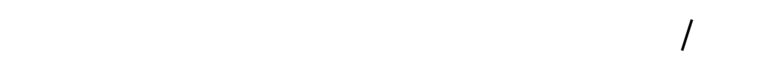

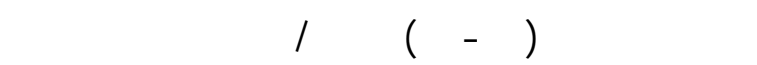

بالجدول رقم r.

رلبا: الكثلكت الملولية للخيواه في عينت البهث: تراومت الكثافت الطاولية لخيوط للسداء المستخمة لعينات البهن

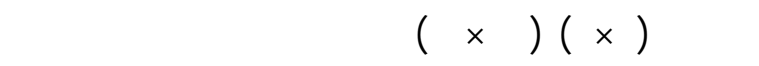

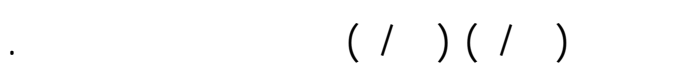

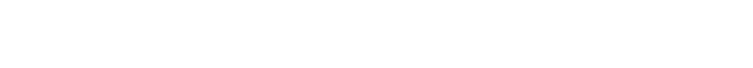

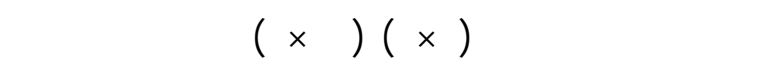

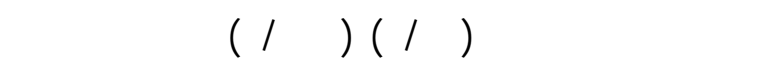
بالجدول رقم (r).

خلمسا: معاملات الغلية للفهشة المستخمة: تراومت معلملات التظية للأفمشة عينت البهث ما بينة (TV) للعينة رقم( (1) البولي لمستر الخالصة وما بين (V) اللعينة رقم(ع) المصنعة من للسداء البولي لمستر واللحمات النايلون كما هو موضضح بالجدول رقم (r). عسامسا: معالل النسج أو الرقم النسهي: تراومت قيم

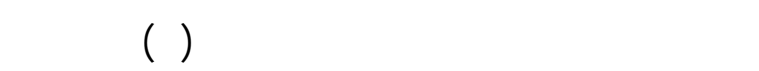

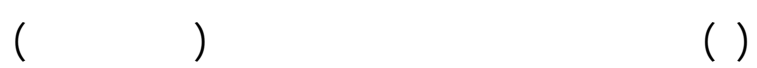

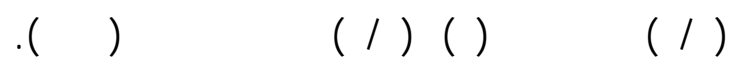

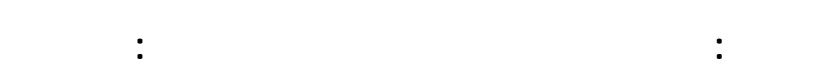

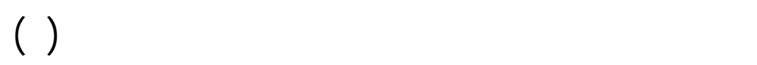

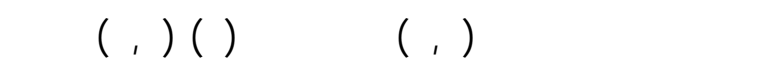
رقم (1).

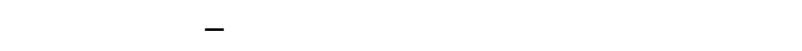

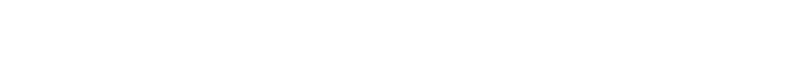

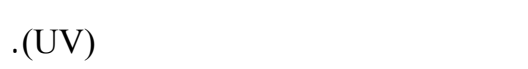
وسلل الاختبار والججهزة المستخمة:

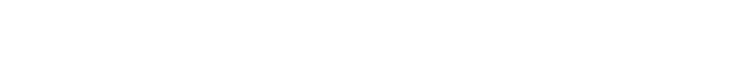
لستخدلم أحد أهم طرق هسلب الارتبط الإحصائي بن اليهن النتائج وهو: عهلب معالمل ارتبط عز المنتج لكارل بيبسون:

Karl Pearson Product-moment correlation coefficient

ويطلق عليها لختصارً (The PPMCC) أو (The PCC) وبلستخدلم المعادلة الآتية: $r=\frac{\sum_{i=1}^{n}\left(X_{i}-\bar{X}\right)\left(Y_{i}-\bar{Y}\right)}{\sqrt{\sum_{i=1}^{n}\left(X_{i}-\bar{X}\right)^{2}} \sqrt{\sum_{i=1}^{n}\left(Y_{i}-\bar{Y}\right)^{2}}}$ حيث: متغير الارتبط X, Y المتوسط المسابي لكل من المتغيرين X, Y النتائج البحثية

عرض لنتئج قيلسلت معالمات التركيب الهنسي النسبي النجية للأفمشة موضنوع البائهي:

يوضنح جدول(r) نتنائج قيلست المواصفلت البنائية

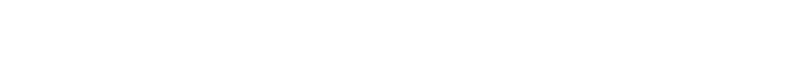
الملابس الخارجية تهت البهث، ومن الجدول يتبين أن:

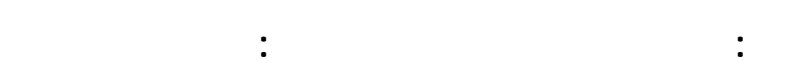

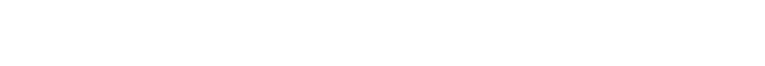

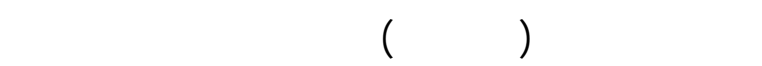

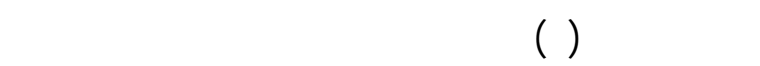

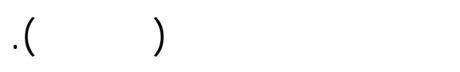

ثلنيا: نوع النسبج أوالترلكيب النسبي المستخم لل الم عينة:

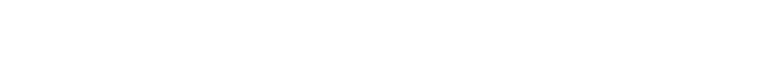




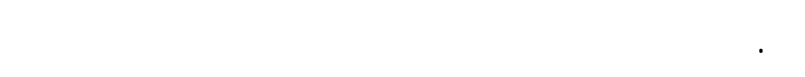

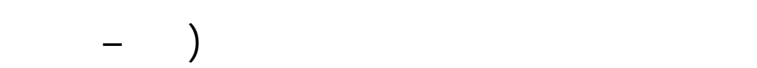
نانوميتر).

ج. من ألجل تحديد ترتيب عينات البهث في مقاومتها لفاذ

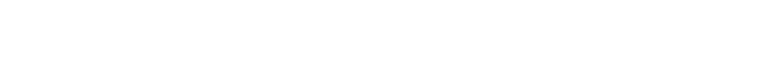
الهسابي العلم لجميع قراءات قيلست فاذ الأشعة (UV) في كل من عينت البهث في جميع المنطق الطيفية (جدول رقم r)

ح. يوضح جدول رقم(ع) ترتيب جميع عينت البحث

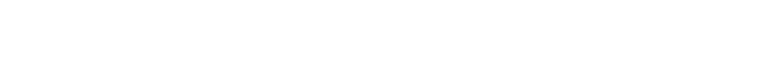
البفسجية في كل منها ترتيباً تصاعياً

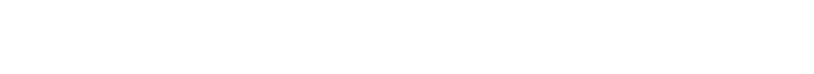

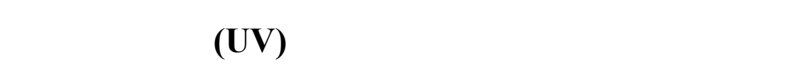
الملابس الخارجية:

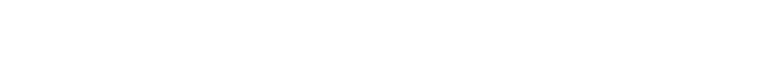

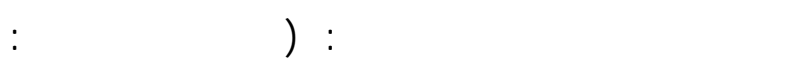

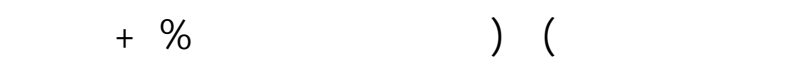

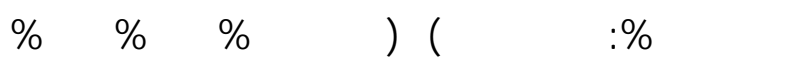

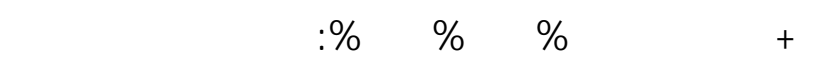

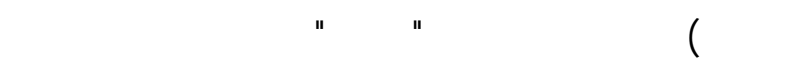

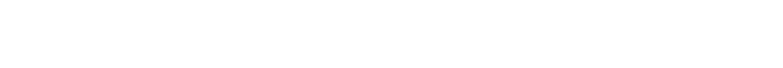
الفاذ الطبيعي لموجلت لأشعة UV في منطققها الثلاث

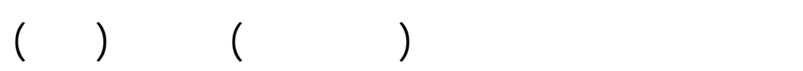

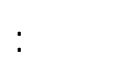

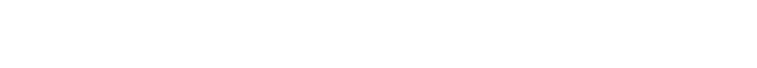

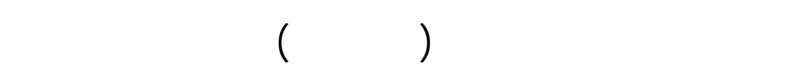

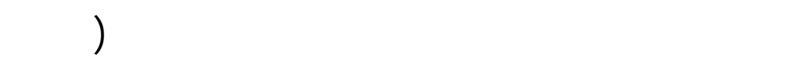

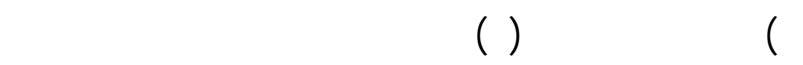
عل جدأ (V) (V) (V)
ثامنا:سطك عينات الفمشة بالمليمتر: تراوحت قيمة سمك

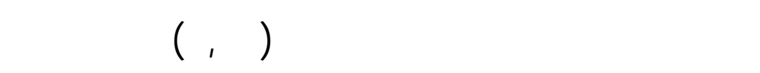
العينة رقم (0)، (07, ·) للعينة رقم (ب).

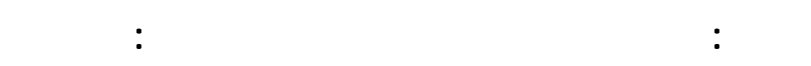

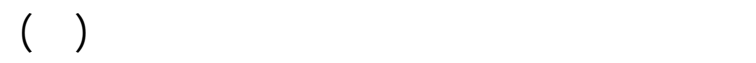

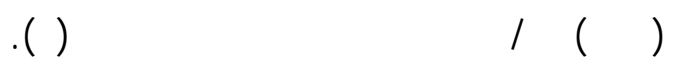
منالفة تحالل نتائج البه: تحالل الأليف الموجية لفاذ الشعة فوف البفسجية خلا عينت البهث: (UV) يتبين من نتائج قيلس معدلات فاذ طيف الأشعة فوق البفسجية (UV) (جدول رقم بّ) ومن الأطيف الموجية لفاذ المٔشعة (UV) خلل عينات الملابس الخارجية موضوع البهث لشكل رقم بـ) ما يأتي:

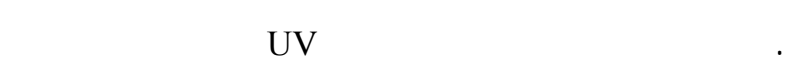

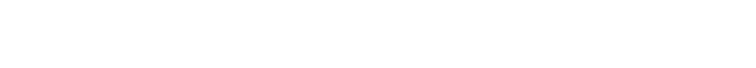

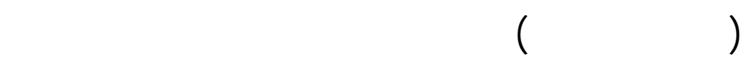
أقصاها في العينة رقم (ع) وأناها في العينة رقم (بّ). ب. تنتحو منحنيك لطيف ففاذ الاشعة فوق البفسجية لجميع عينات البهث مناحي متشابهة في الطاوليال الموجبة القصيرة حيث تألخذ منحنياتنها اتجاها تنازلياً يبدأ

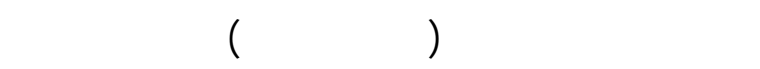

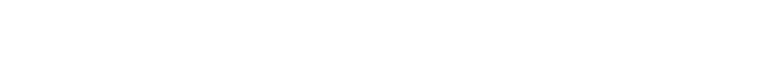

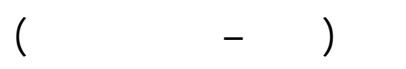

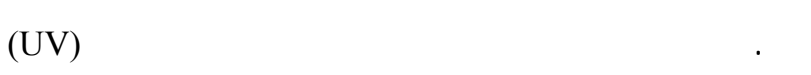

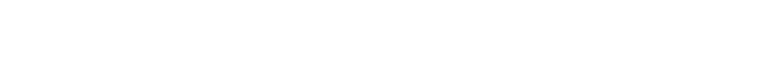

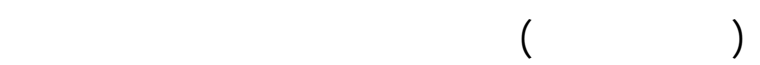

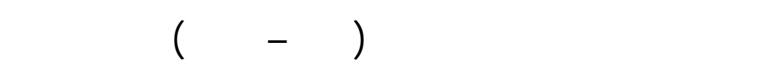

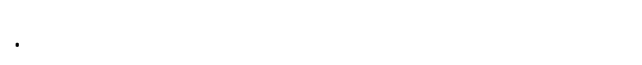




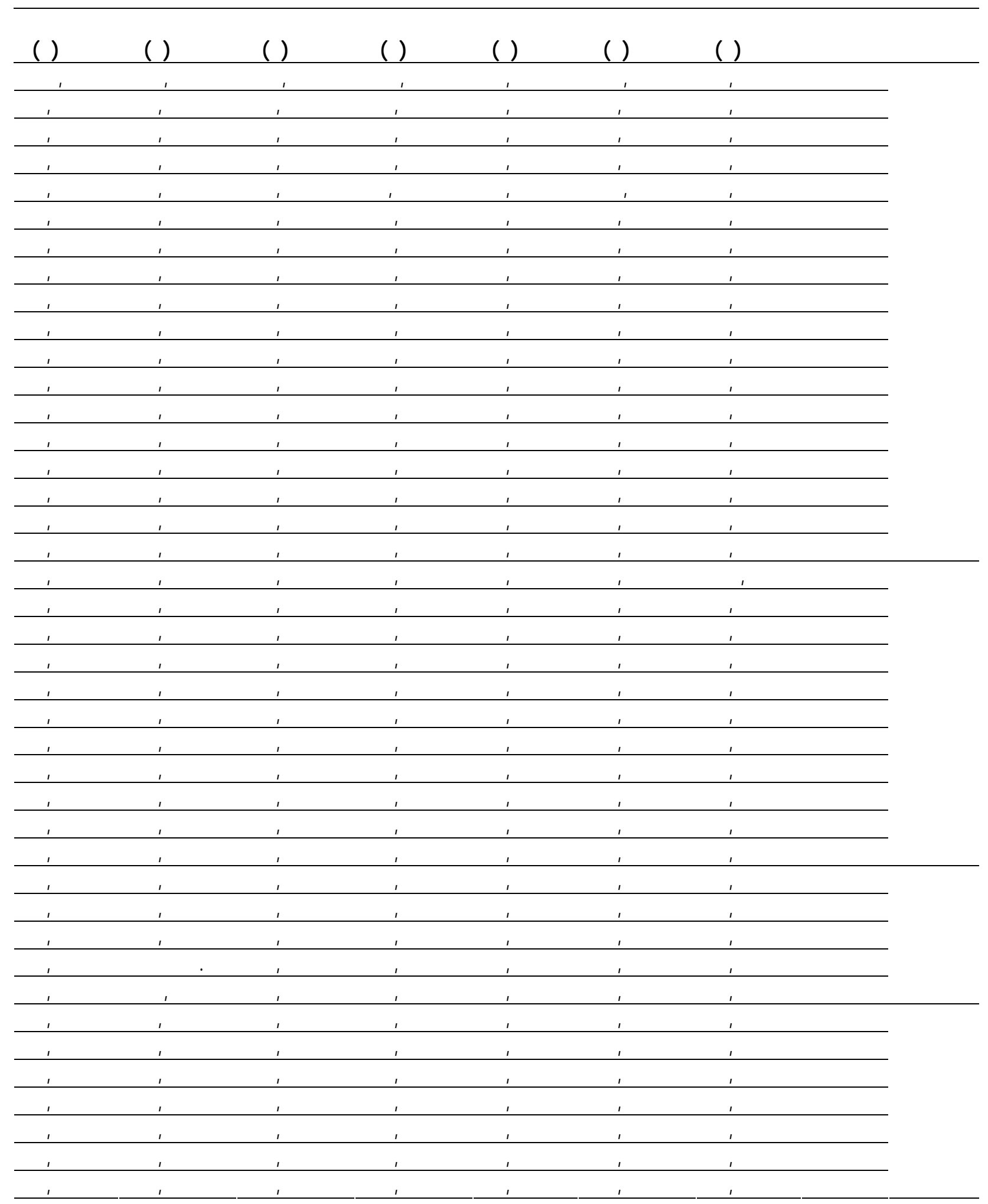


جيهان محمود عبدالحميد، وفاء محمد محمسملحة: فعالية معلملات التركيب الهنهي النسبي ...

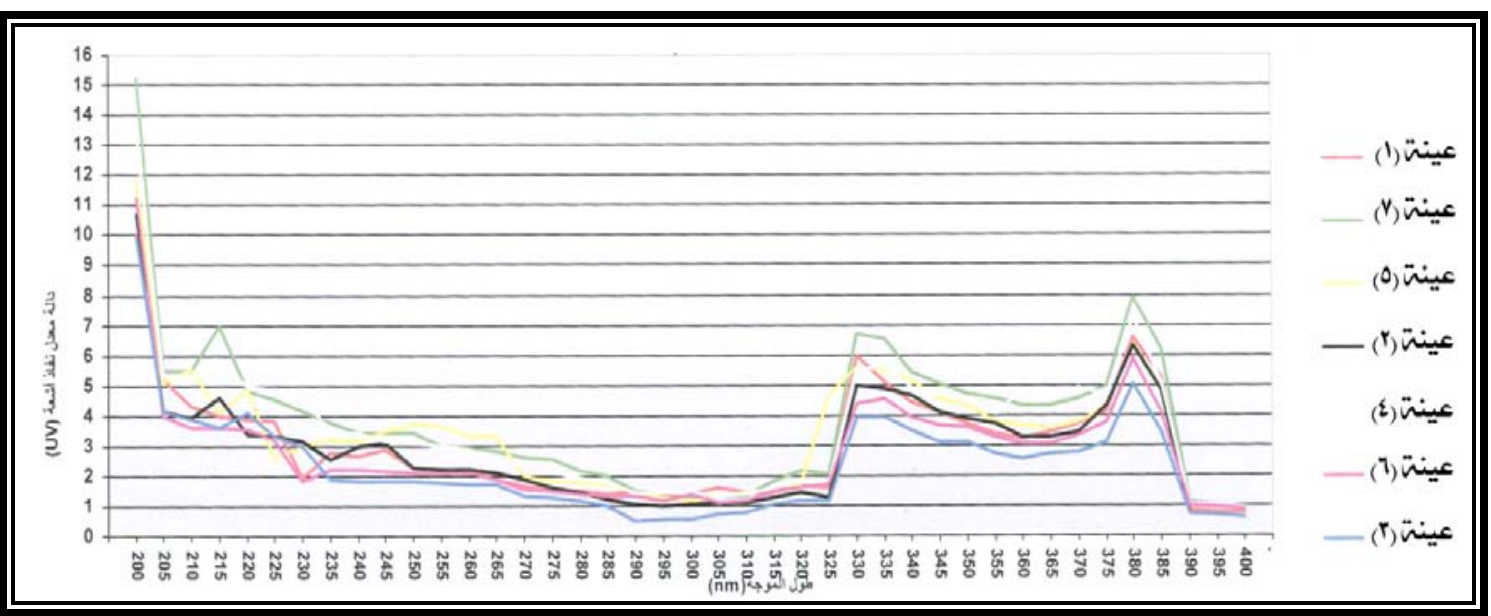

شئل رقم r. اللف الموجي لفاذ لأشهةفوق البفسجية لعينا الملابس تهات البهث

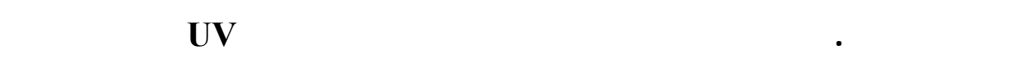

\begin{tabular}{|c|c|c|}
\hline المتوطط العلم لمعل فلذ UV خلالها & ومف وموجز اللعينة & رقتم العينة \\
\hline 1,9 & 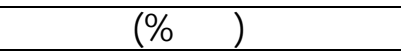 & \\
\hline$r, \mu \mathrm{V}$ & نايليلن × بولي لمتر فلمِلس & 7 \\
\hline$r, \varepsilon$. & 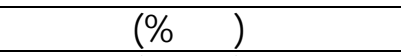 & $r$ \\
\hline$r \cdot \pi$ & 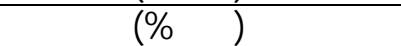 & 1 \\
\hline$r, 11$ & 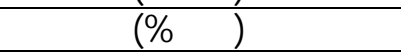 & $\varepsilon$ \\
\hline$r, r$. & نايلون × بولي لمترسادة & $\mathrm{v}$ \\
\hline$\mu, \mu$ & نايلاون X بولى لمتر رسادة & 0 \\
\hline
\end{tabular}

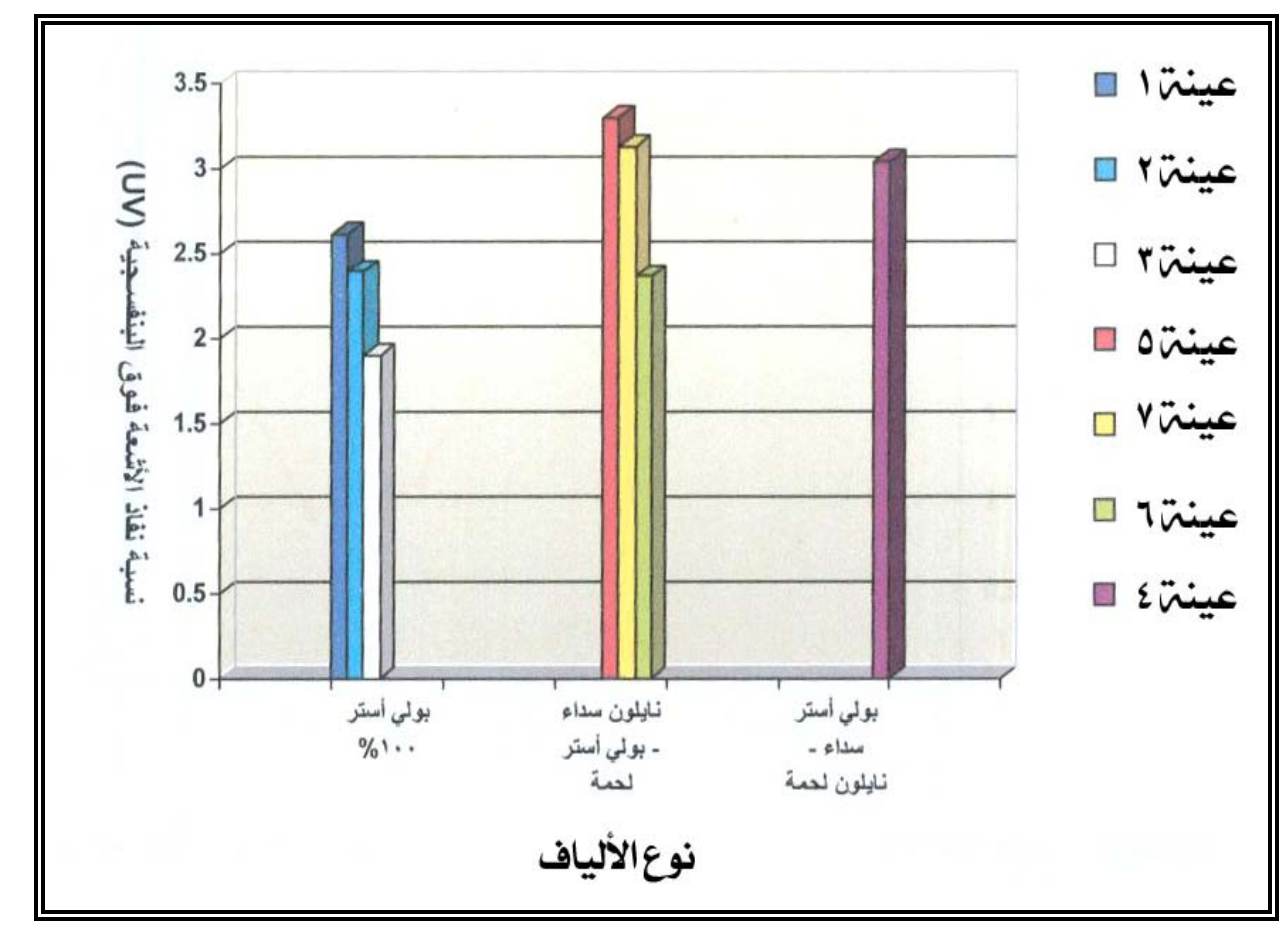

شأل ع. تأثير النركيب اللثعري لعينت البهث عل نسبة فاذ الأشعة فوق البفسجية(UV) خلالها 
اللتركيب النسجي للقملث أثر كبير في معل فاذ الأثعة فوق البفسجية فيه حيث نجد أن العينت المنسوجة بتركيب

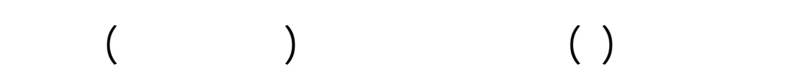

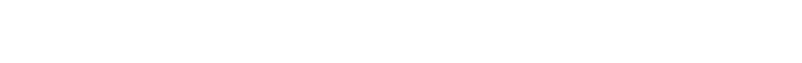
كذك تفوقت على العينة(ع)، ذات التركيب النسجي للساة

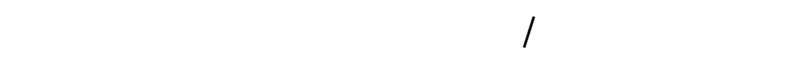

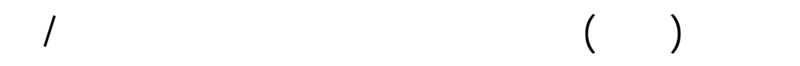
وهذا يجيب النساؤل الاول من البهث.

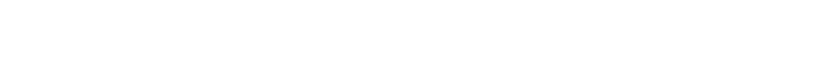
العينت علل الفاذ الليقي لأشعة (UV):

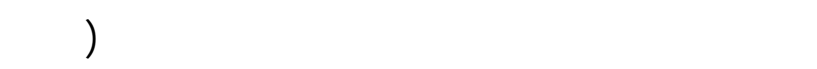

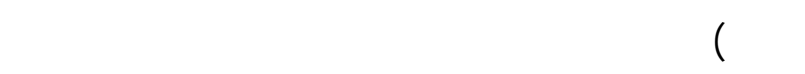

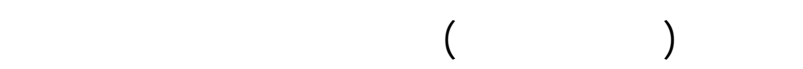

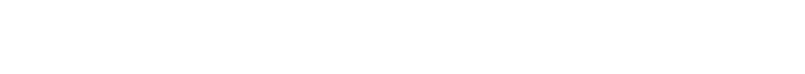

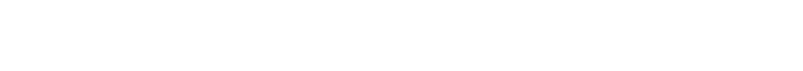
البفسجية ويجيب ذلك على تساؤلات البهث الثانى:

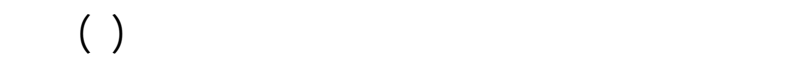

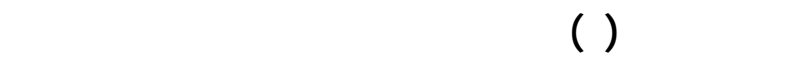
للمنطق الطيفية الثلاثة من الأشعة فوق البفسجية.

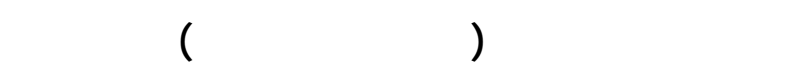
اللمي للأشعنفوق البفسجية (UV):

بتصنيف عينات البهث تبعاً لمعلملات النسج أوالترلكيب البهاب النسية نجدها تحتوي على ثلالثة مجموعات هي:

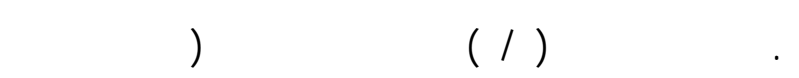
اللحمة)

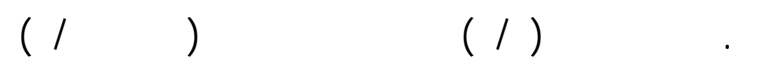
ج.معلمل نسبج (Y/Y/T) للأقمشة المنسوجة (بللساة الممتد (T)

وبمقارنة الخواص طيفية للثلاث مجموعات من خلال جدول رقم (س) والأشكل من (سا، 0) يتبين أن:

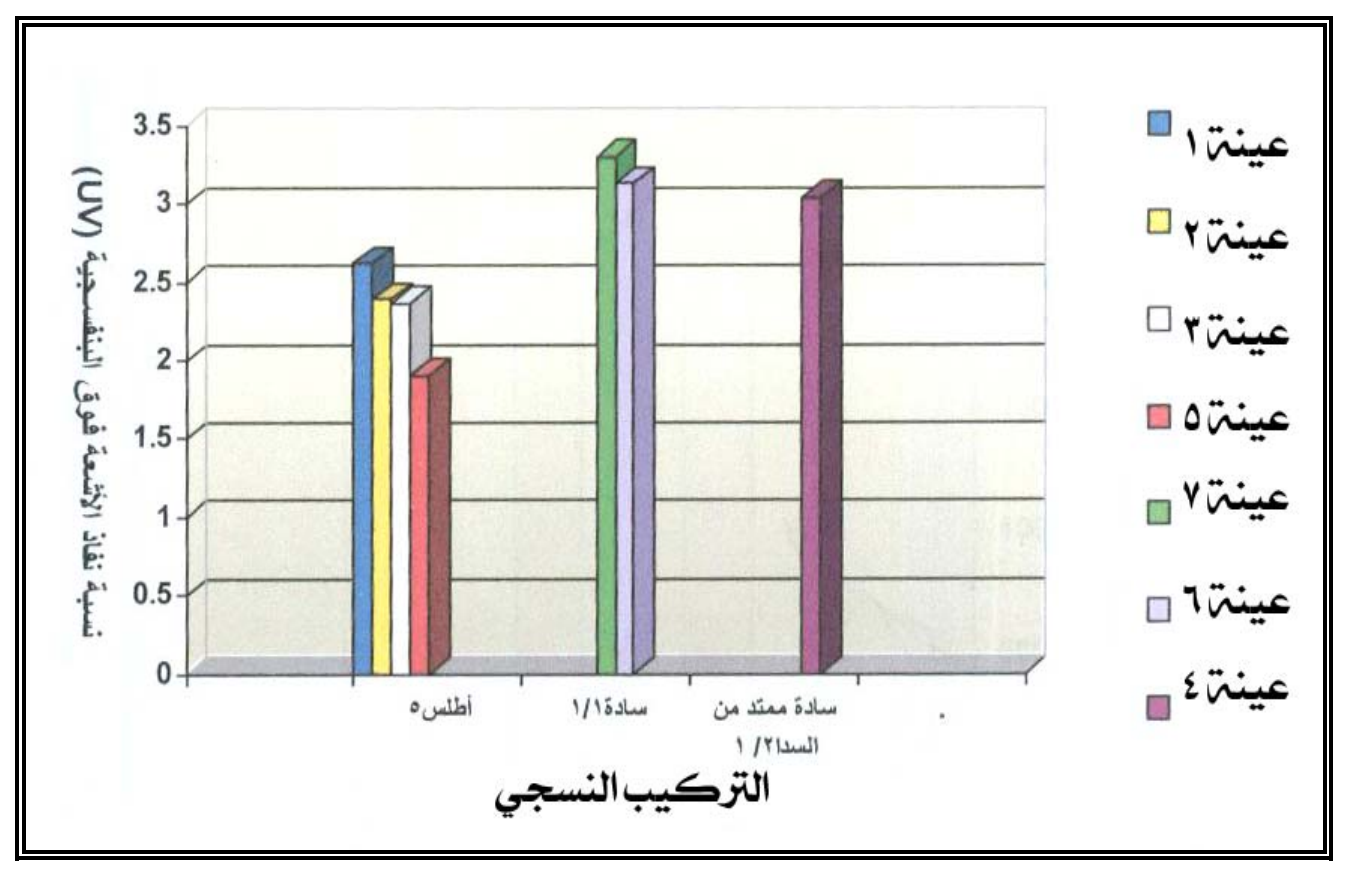

شظك 0. تأثير التركيب النسجي لعينت البهث عل غسبة فاذ أشعة(UV) خلالها 
مجلة الإسكندرية للتبال العله - (مجلد 7ب العدد (1) يناير -مارس 10 •r

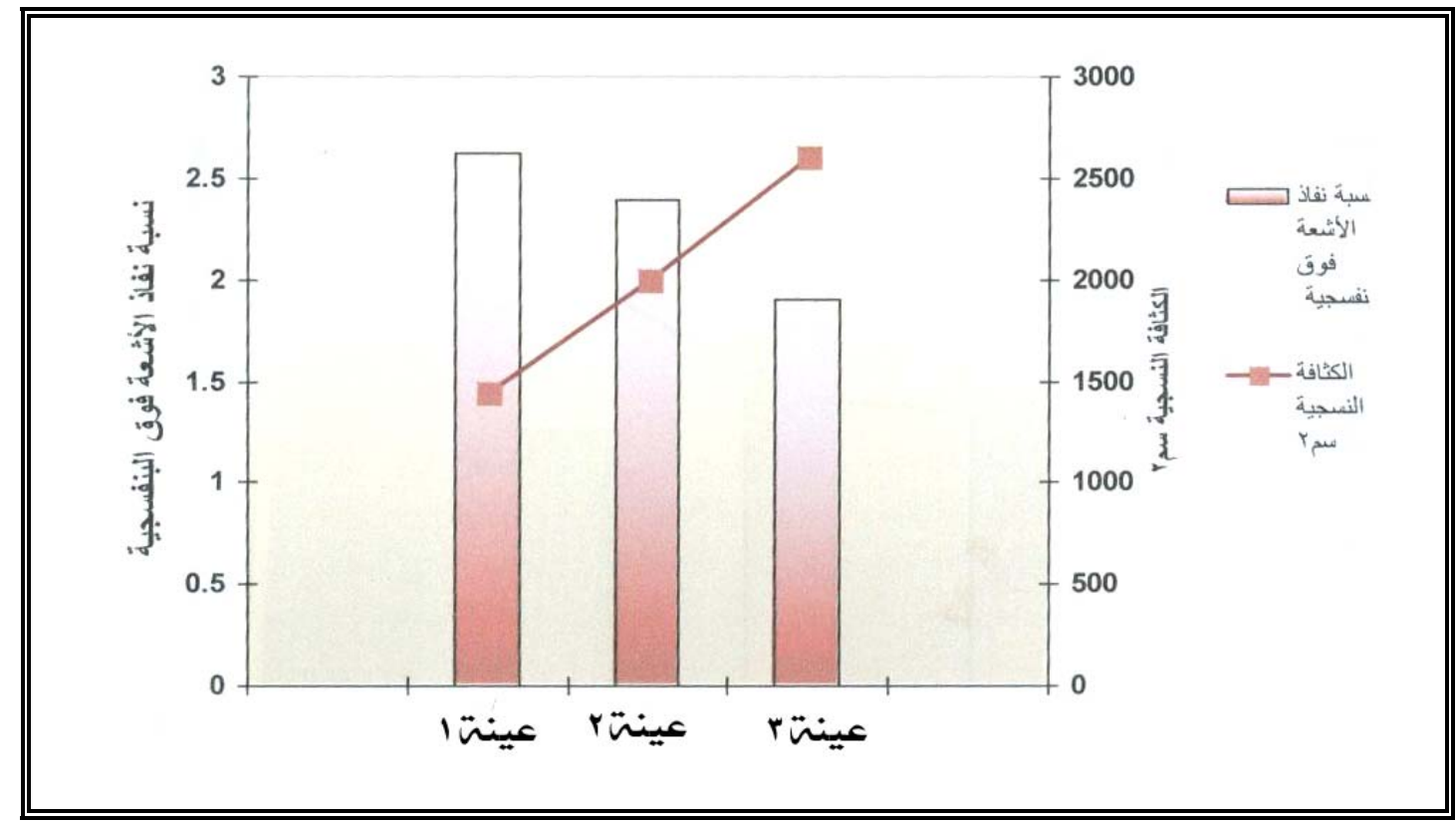

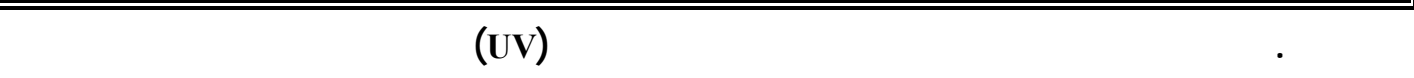

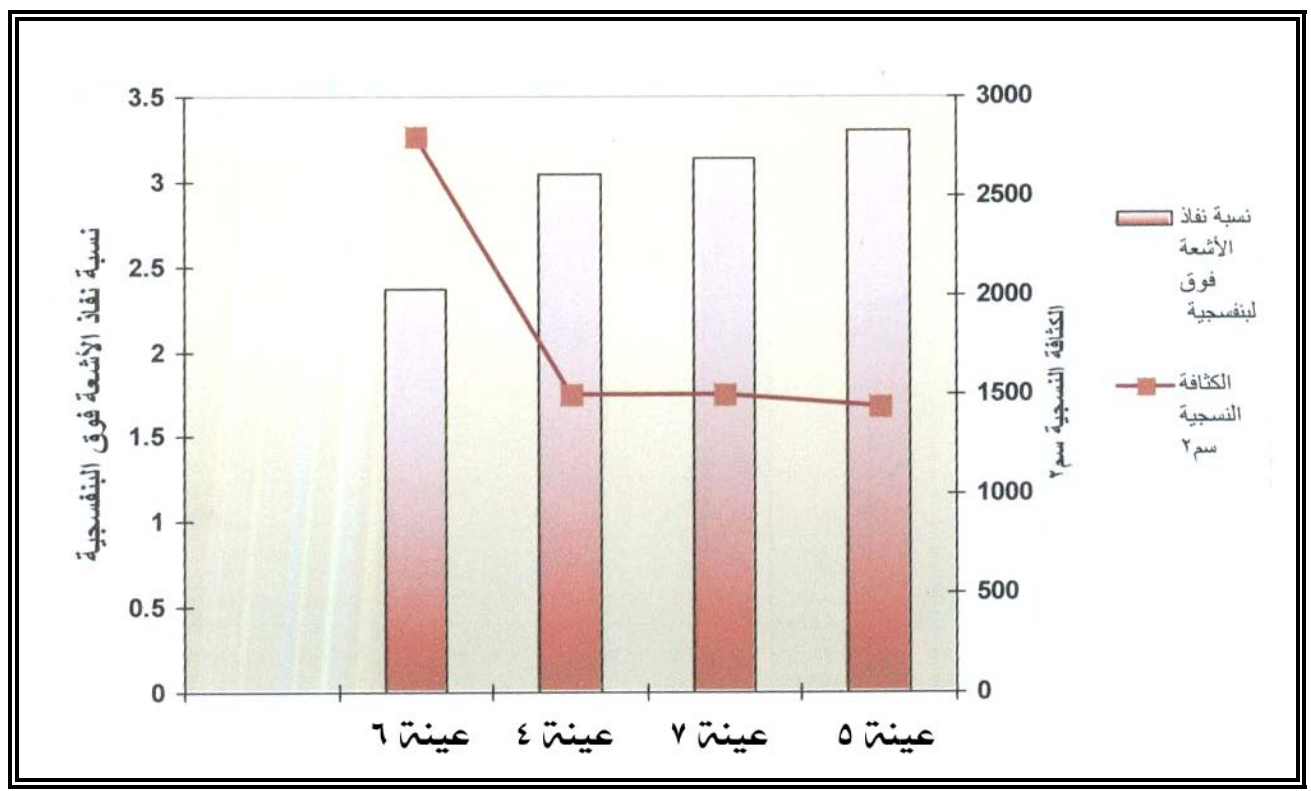

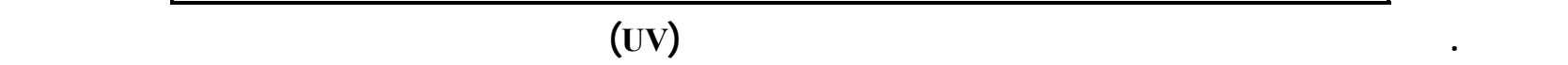

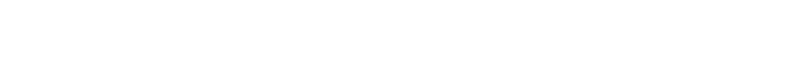

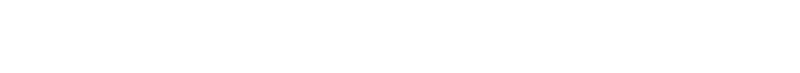

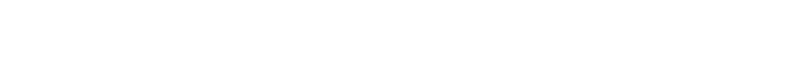

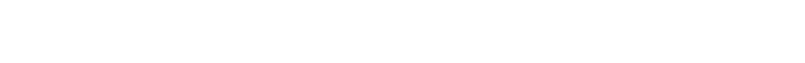
فوق البفجية(UV) خلالها: لطوالها الموجية.

باعتبار أن معلمل التطية النسجية معلملاً هنهسياً بهت

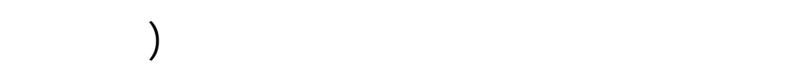
في دلخلها الكثافت النوعية والحجمية للشعيرات المكونة منها وعولمل هنهسة الخط جميعها) وبين الكثافة العدية التهات 


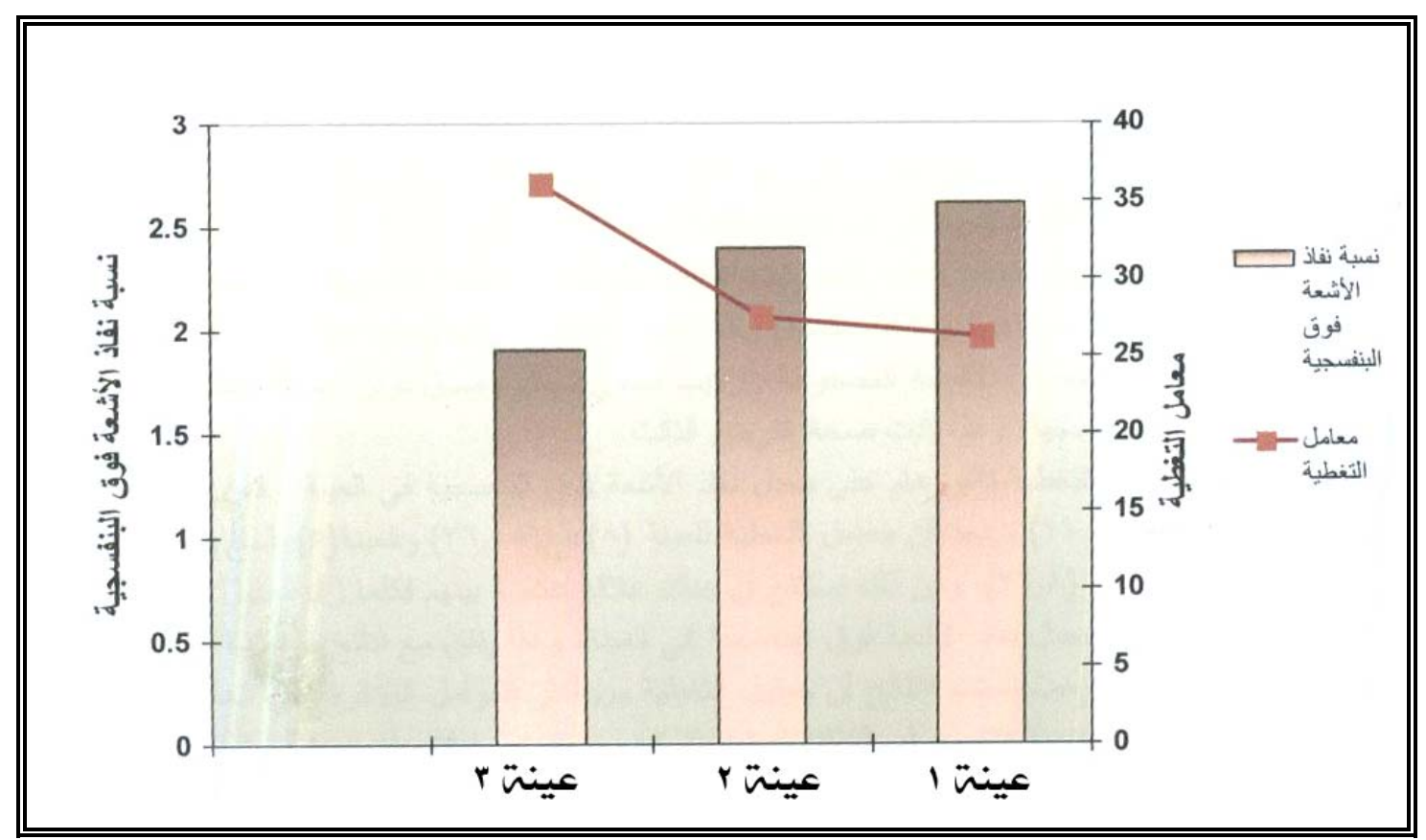

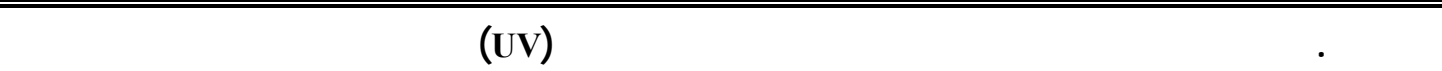

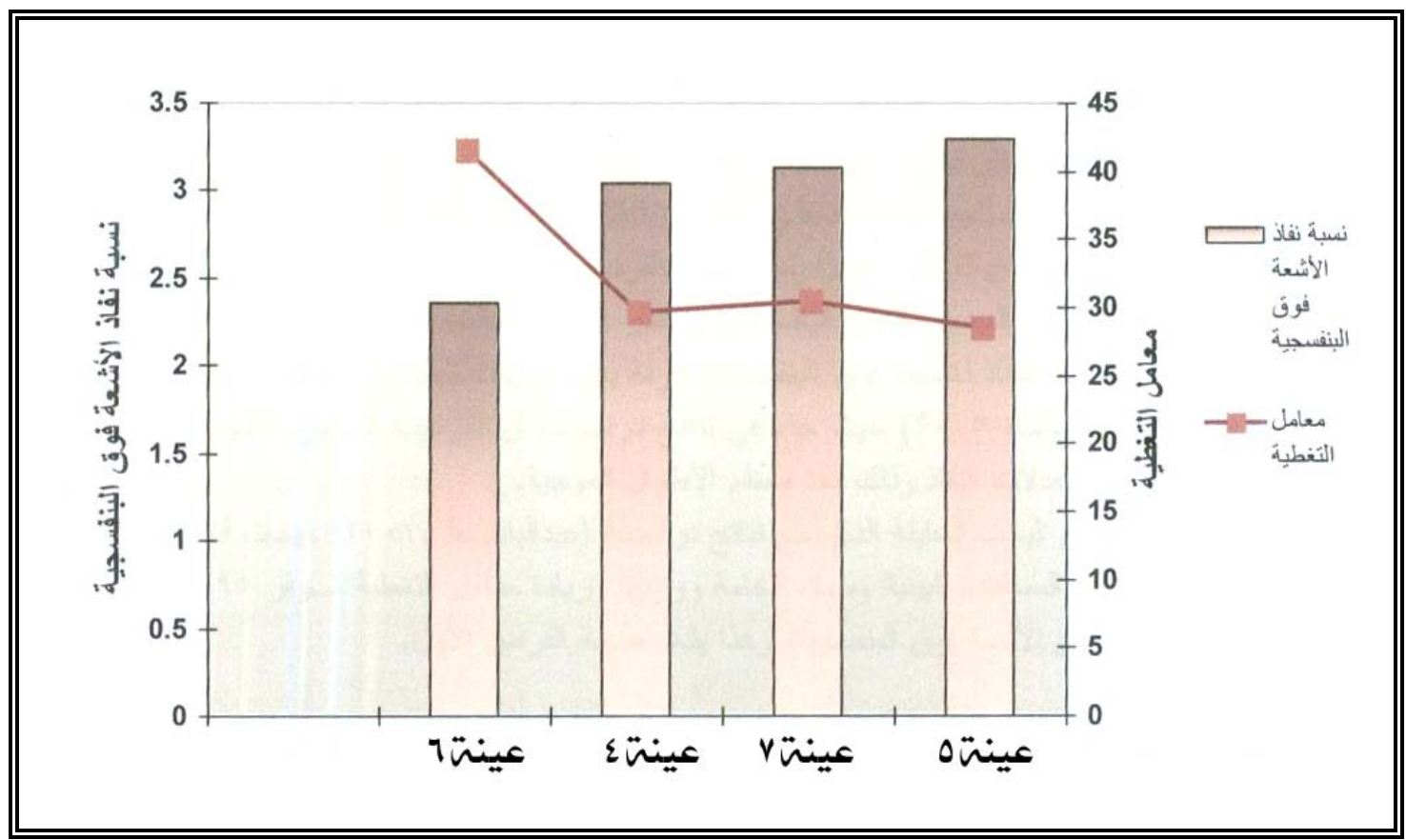

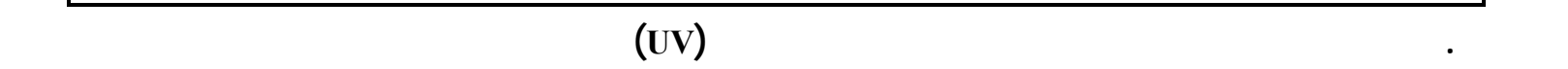

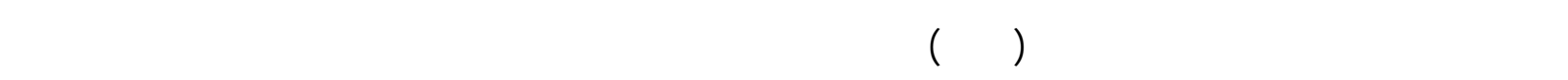

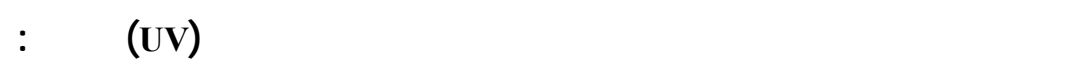

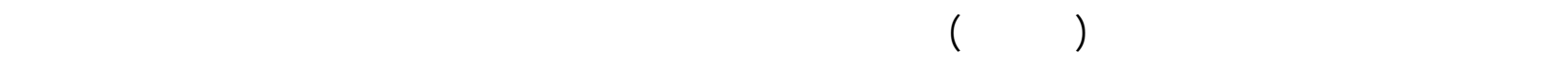

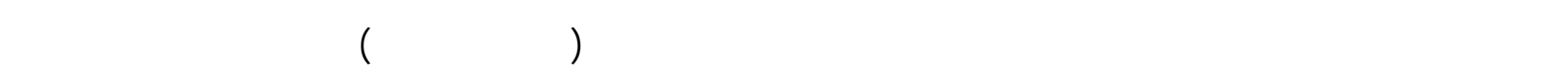

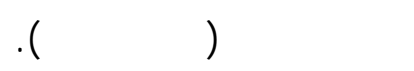




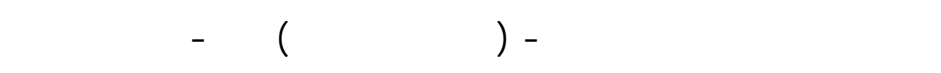

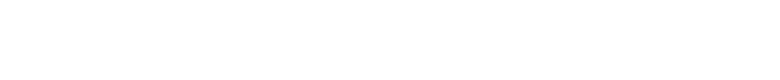
لستخده لحد أهم طرق هسلب الاستنبط الإحصائي بين النتائج وهو مسلب معلمل ارتبط اهذ عزم المنتج لكارل Karl Pearson Product-moment correlation

بيرون

حيث عل coefficient بلستخدd المعادلة رقم (0) النيسق نكرها وذلك لتوضبح

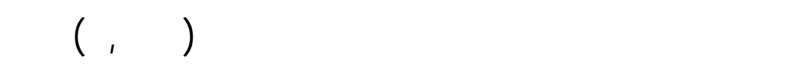
عولمل التركيب البنائي موضوع الدرلسة(متغيرات الدرلسة)

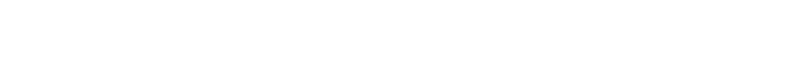
عند جمبع الأطول الموجية(القصيرة- المتوسطة- الطويلة)
خواص الأشعة الكهرومغنطيسية (أيا كانت لُألاوالها الموجية) وتفق نتائج هذا البحث مع هذه الحقيقة العلمية كما

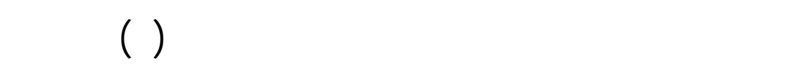

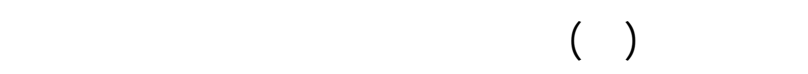

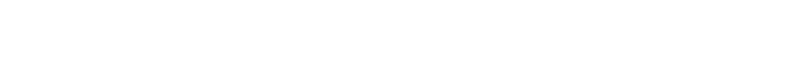
علاقة عكسية بينها وتجيب هذه النتائج على التساؤل الثالث. (جدول (0)

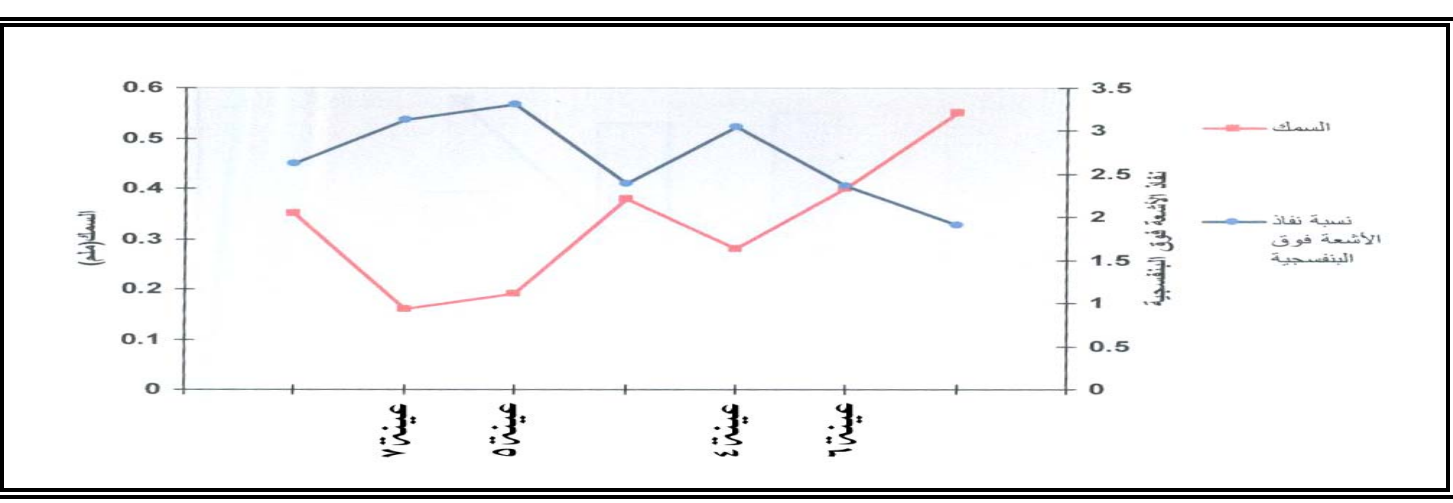

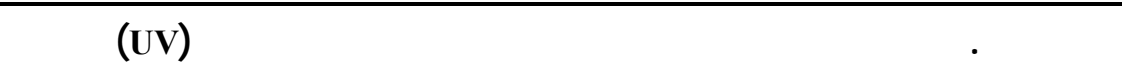

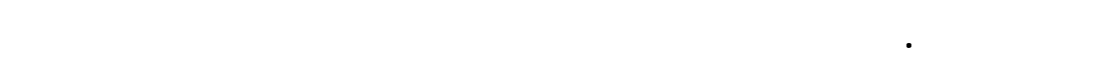

\begin{tabular}{|c|c|c|c|c|c|c|}
\hline ل اللسط & النسجيب & النغلية & النسجية & لأليف عi & لارتبلا والدلالة الإحصائية الهنية الهنسية & $\begin{array}{l}\text { المنللاق اللمفية (UV) } \\
\text { (UV) }\end{array}$ \\
\hline$\cdot 97 \%$ - & $\cdot, 7 \cdot r-$ & $\cdot$ •, ह૧ - & $\cdot, \mathrm{V} \wedge \mathrm{Y}^{\mathrm{\mu}}-$ & $\cdot, \mathrm{V} 90-$ & معلمل مبيرون & \multirow{3}{*}{ 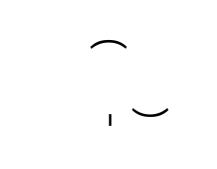 } \\
\hline$\cdot, \cdots$ & $\cdot, \cdot \varepsilon r$ & $\cdot, \mathrm{rV} \cdot$ & $\cdot, \cdot \mu \Lambda$ & $\cdot, \cdot \mu \mathrm{O}$ & مستوى الدلالة & \\
\hline دلالة إلحصائياً & ل & غير دائيً & ل & ل & الدلالة الإحصائية & \\
\hline$\cdot, 9 Y V-$ & $\cdot, 770-$ & $\cdot, \mathrm{YV} \mathrm{VO}-$ & $\cdot, \mathrm{V}>\mathrm{N}^{\mathrm{\mu}}-$ & $\cdot, 7 \varepsilon \varepsilon-$ & معلمل بيريسون & \multirow{3}{*}{ 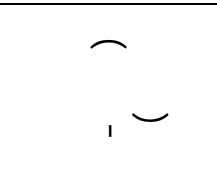 } \\
\hline$\cdot, \cdot r$ & $\cdot, \cdot 10$ & 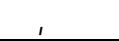 & $\cdot, \cdot \varepsilon \Lambda$ & $\cdot, 119$ & مستوى الدلالة & \\
\hline دلالة عالية جدائاً & لجصائيَ & غير دائيً & ل إحصائياً & غير دائيً & الدلالة الإحصائية & \\
\hline - & - & $\cdot$, EVI - & - V r - & $\cdot$, AYV - & معلمل ب...يسون & \multirow{3}{*}{ 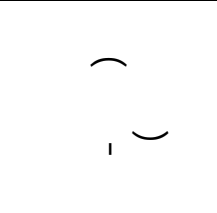 } \\
\hline$\cdot, \cdot 1 r$ & · & $\cdot, r \wedge \varepsilon$ & $\cdot, \cdot \varepsilon 0$ & $\cdot, \cdot r \mid$ & مستوى الدلالة & \\
\hline دلالة إحصائياً & غير دائيً & غير دائيً & ل & دلأحصائياً & الدلالة الإحصائية & \\
\hline
\end{tabular}




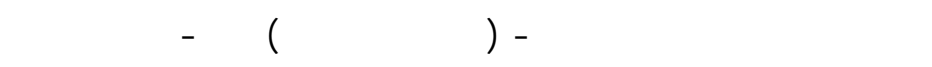

السمان - سلمية إبراهيم لطفي: موسوعة الملابس، جلمعة

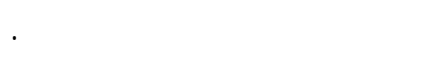

زاهر،سمير لحمد، لختلاف نسب الخلط للشعيرات على الخواص

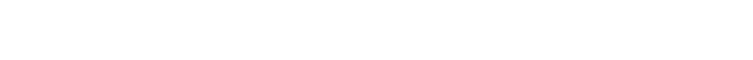

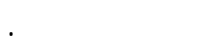

عيس،شيرين مجدي، درلسة مواصفلت الأقمشة المستخمة في ويدو، صناعة مفروشكت للسيارات، بسالة ملجستير غير منشورة،

$$
\text { كلية الهنهة، جلمعة الإسكندرية، ع. - r. }
$$

AATECC test method 183. transmittance or blocking of erythemally weighted UVR through fabrics, 2004.

Denton. M. J, Textile Terms and difinitions- $11^{\text {th }}$ edition, the textile iristitute, Manchester, England, 2002.

Dubrovski, D. P. \& Gobb, D.; Effects of woven fabric construction and color on UVP. Tex, Res. J., Vol 79, No. 4, 351-359, 2009.

El-Gamal M. A., Fabric Structure, Part1, $21^{\text {st }}$ edition Dar ElIslam, Mansoura, Egypt, 2012.

Gabrijelcic, H., Influnce of fabric constructional parameters and thread color on UV protection fibers and textiles in Eastern Europe, Vol. 17, No, 1, 46-56, 2009.

Gies, P.H., Protection against solar radiation, mutaltion research fundummental and molecular mechanism mugensis, Vol. 422, No, 1, 15-22, 1998.

Harby, Mahmoud, Fabric Geometry, Ffaculty of applied arts Pub. Egypt, 2010.

Hatch, K. L. \& Osterwalder, V. Garments as solar UVR screening materials dermatologic clinics, Vol. 24, No. 1, 85-100, 2006.

Hustvedt G.. Textile technology: the UVPE of naturallypigmental cotton, J. Cotton. Sc., Vol. 9, No. 1, 2005.

Riva, A. Modeling the effects of colour on the protection provided by cotton woven fabrics dyed with azo dystuffs. Industrial \& Engineering chemistry research, Vol. 48, No. $22 \mathrm{~m}$ 9817-9822.

Roy, C. R. The Solar UV radiation environment, journal of photochemistry and photobiology, B; biology, Vol. 31, No. 1-2, 21-27, 1995.

Scott, R. A., Texiles for protection, woodhead publishing limited, Cambridge, England, 2005.

Stankovic, S. B., UVPF of gray-state plain cotton knitted fabrics, Tex. Res. Journal, Vol. 79, No. 11, 1034-1042, 2009.

Willson, C. A.. Solar protection effects of selected fabric and use characteristics in UV transmission. Tex, Re. journal. Vol. 78, No. 2, 128-137, 2008.
يخلص هذا البحث في أهمية الأخذ بلسلوب التحليل العلهي الدقق للعولمل البنائية الهنهية التي تمل البنية

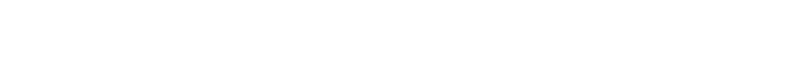
تأثيرسقوط أي نوع من الموجلت الكهرومغنطيسية عليها.

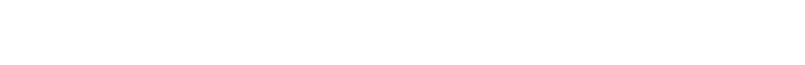
العولمل الهنهية التي تشكل بناء لنسجة الملابس الخارجية

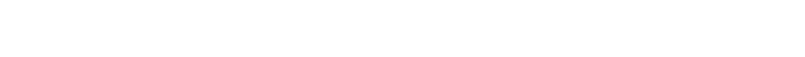

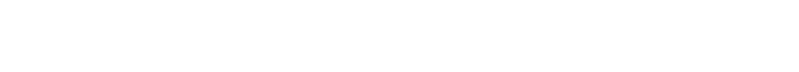
المختلفة(قسمت ثلاث منطاق طيفية قصيرة ومتوسطة وطويلة) وقد توصل البحث إلى مجموعة من النتائج الهلمة تنعكس فائتتها الظرية والعملية بشكل ظبيقي عند اليهن الرغبة في لختيار التركيبت للشعرية الأمل حيث حددها البحث

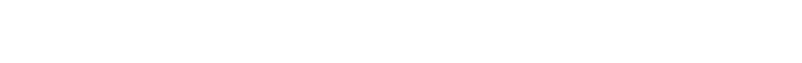

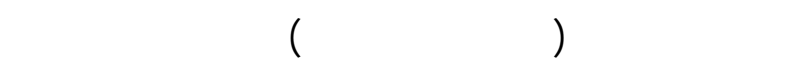

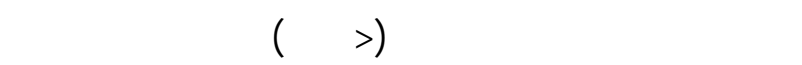
للخيوط (1 - I تكس) وتخانات الأفمشة الأثثر فعالية

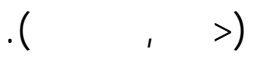

\section{المـ رلجحثع}

إبراهيم،سعدية عمر. تأثير لختلاف الخلمة على خواص متانة الأقمشة، علوم وفنون درلسلت وبحوث، المجلد الخلهس

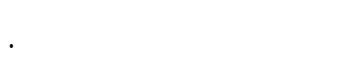

إبراهيم، سعدية عمر. تأثير لختلاف الخلمة على الخواص

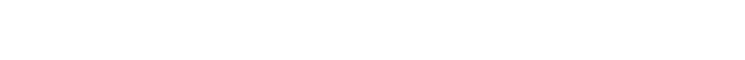
المجلد الرليع عثر، العدد الثالث، r. r. r.

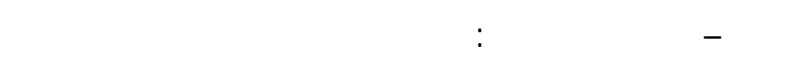
النجية- الطبعة العلثرة - الجزء الأول: الأنسجة الرئيسية-

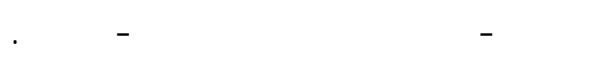

للسملن -سلمية إبراهيم لطفي: علم المنسوجلت - الطبعة الأوله- - داله

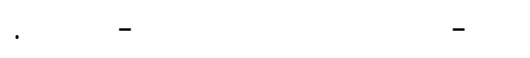




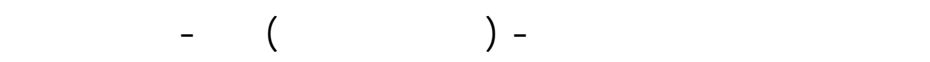

\section{The Efficiency of Woven Geometrical Parameters in Resisting Harmful Ultra- Violet Radiation Wave Lengths through The Outer-Wear}

Gehan Mahmoud Abdel Hamid, Wafaa Mohamed Samaha

Outer-wear is the external layer which as responsible for than $90 \%$ from dealing with UV where falls on the perso. body. an important value in this paper is designed to investigate the clothes esisting efficiency against harmful UV radiation. So it to determine the more effective texture structural factors, in relation to the UV transmission properties of the light.

Fiber content, Weave structure, clothing density, yarn density, fabric thickness, porosity and fabric weight were tested. PPMCC statistical method was used for analyzing the research results. Polyster blended with Nylon, woven with plain weaves showed inferior UV protection properties. Pure polyster fabrics woven with sateen structure have the best hygienic properties for resisting the transmittance of UV radiation either in short, medium or long regions (i.e. $200-400$ nanometer). 
جطط رقم r. الموالصفلت البنائية الهنعية للينت البهث

\begin{tabular}{|c|c|c|c|c|c|c|c|c|c|c|c|c|c|c|}
\hline \multirow{3}{*}{ لأفهنة } & \multirow{3}{*}{ بالفهشة } & \multirow{3}{*}{ (الغتبح النسبي المسامية } & \multirow{3}{*}{ اللغلفلة النفشة } & \multicolumn{4}{|c|}{ الكثافة اللولية الخيوا } & \multicolumn{2}{|c|}{ الكثلة العدية في } & \multirow[t]{3}{*}{ النسبلج } & \multirow[t]{3}{*}{ النسبج } & \multirow{3}{*}{ لخالا للالثعيرلت المئوبة } & \multirow[t]{3}{*}{ التركيب الثمري لبساء } & \multirow[t]{3}{*}{ رقهينة } \\
\hline & & & & يير & & & Si & لحملت & عسداء & & & & & \\
\hline & & & & لحملت & ع ع & لحملت & عسداء & & & & & & & \\
\hline $1 \cdot V$ & ( & 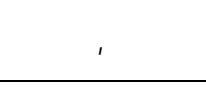 & rV & $(1 / V Y)$ & $(I / V Y)$ & $(1 \times n)$ & $(1 \times 1)$ & ro & عا & $0 / \Gamma$ & 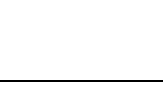 & . . . ا\% بولي طستر & 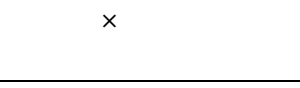 & 1 \\
\hline $1 \cdot 7$ & $\cdot, \mu$ & $r, 0$ & $r \Lambda$ & (1/99) & $(1 / 0 \varepsilon)$ & $(|x|+)$ & $(1 \times 7)$ & rq & 01 & $0 / \Gamma$ & لَّل سل من اللحمة 0 & . . ام\% بولي لستر & نبولي لم تحر × +ـ -ولي & $r$ \\
\hline iro & $\cdot, 07$ & $r, \Lambda$ & 17 & $(\mathrm{I} / \mathrm{OO})$ & $(I / V Y)$ & $(I \times Y)$ & $(1 \times 1)$ & عا & $7 \varepsilon$ & $0 / \Gamma$ & لَلا سل اللحمة 0 & . . ا\% بولي لستر & لمولي لس تر × + -ولي & $\mu$ \\
\hline 111 & $\cdot r \Lambda$ & $1, \varepsilon$ & V. & (।/११) & $(1 / 0 \varepsilon)$ & $(|\times| \mid)$ & $(1 \times 7)$ & rq & 01 & $\mu / \Gamma$ & 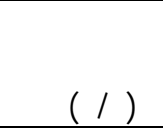 & 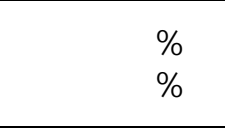 & بولي لستر× ×ايلون & $\varepsilon$ \\
\hline $1 \cdot r$ & $\cdot, 19$ & $\mu$ & $\mu$. & (I/VY) & (।/११) & $(1 \times n)$ & $(|\times|)$ & ro & $\varepsilon 1$ & $r / r$ & س - (1/1) & 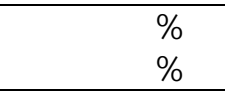 & نايلون × بولي لمتر & 0 \\
\hline ع & ( & $r, \varepsilon$ & $\varepsilon r$ & $(\mathrm{I} / \mathrm{OH})$ & (।/৭৭) & $(I \times \mid V)$ & $(|\times| \mid)$ & rq & VI & $0 / r$ & لطل سل 0 & 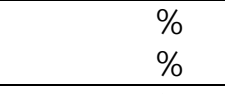 & نايلون × بولي لمستر & 7 \\
\hline V7 & $\cdot, I V$ & $r, \mu$ & $\mu$ & $(|\times| V)$ & (।/৭৭) & $(|X| \mu)$ & $(|\times| \mid)$ & $r \varepsilon$ & 71 & $r / r$ & 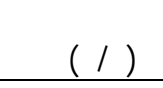 & 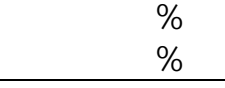 & نايلون X بولي لستر & V \\
\hline
\end{tabular}

